\title{
Establishment of a Comprehensive List of Candidate Antiaging Medicinal Herb Used in Korean Medicine by Text Mining of the Classical Korean Medical Literature, "Dongeuibogam," and Preliminary Evaluation of the Antiaging Effects of These Herbs
}

\author{
Moo Jin Choi, ${ }^{1}$ Byung Tae Choi, ${ }^{2}$ Hwa Kyoung Shin, ${ }^{2}$ Byung Cheul Shin, ${ }^{3}$ \\ Yoo Kyoung Han, ${ }^{1}$ and Jin Ung Baek ${ }^{1}$ \\ ${ }^{1}$ Division of Humanities and Social Medicine, School of Korean Medicine, Pusan National University, \\ Yangsan 626-870, Republic of Korea \\ ${ }^{2}$ Division of Meridian and Structural Medicine, School of Korean Medicine, Pusan National University, \\ Yangsan 626-870, Republic of Korea \\ ${ }^{3}$ Department of Korean Rehabilitation Medicine, Pusan National University Korean Medicine Hospital, \\ Yangsan 626-789, Republic of Korea \\ Correspondence should be addressed to Jin Ung Baek; mukjagan@pusan.ac.kr
}

Received 10 September 2014; Revised 3 January 2015; Accepted 8 January 2015

Academic Editor: Shun-Wan Chan

Copyright (c) 2015 Moo Jin Choi et al. This is an open access article distributed under the Creative Commons Attribution License, which permits unrestricted use, distribution, and reproduction in any medium, provided the original work is properly cited.

The major objectives of this study were to provide a list of candidate antiaging medicinal herbs that have been widely utilized in Korean medicine and to organize preliminary data for the benefit of experimental and clinical researchers to develop new drug therapies by analyzing previous studies. "Dongeuibogam," a representative source of the Korean medicine literature, was selected to investigate candidate antiaging medicinal herbs and to identify appropriate terms that describe the specific antiaging effects that these herbs are predicted to elicit. In addition, we aimed to review previous studies that referenced the selected candidate antiaging medicinal herbs. From our chosen source, "Dongeuibogam," we were able to screen 102 terms describing antiaging effects, which were further classified into 11 subtypes. Ninety-seven candidate antiaging medicinal herbs were selected using the criterion that their antiaging effects were described using the same terms as those employed in "Dongeuibogam." These candidates were classified into 11 subtypes. Of the 97 candidate antiaging medicinal herbs selected, 47 are widely used by Korean medical doctors in Korea and were selected for further analysis of their antiaging effects. Overall, we found an average of 7.7 previous studies per candidate herb that described their antiaging effects.

\section{Introduction}

Recently, a number of studies have been conducted that pursue the active development of antiaging drugs. Many researchers develop novel drugs by exploring the antiaging constituents of herbs that are widely used in traditional medicine in many countries around the world. For example, in previous studies, preliminary data were identified by searching for candidate herbs in the traditional medicinal literature and then evaluating the antiaging effects of these candidates (e.g., $[1,2])$. However, thus far, such studies have been conducted only within the traditional Chinese literature, while the Korean literature remains to be analyzed.

Therefore, we have reviewed a representative source of classical Korean medical literature as a means of providing useful preliminary data, as has been done previously with the Chinese literature. There are several justifications for selecting "Dongeuibogam," which was published in 1613, for analysis in the present study; (1) it was published by the royal physicians, who were contemporary experts that strictly upheld the traditions of basic Korean medicine (KM); from ancient to present times, KM has been developed via 
exchange with adjacent countries such as China and Japan. Recently, this traditional medicinal science has contributed to academic development as well as to the improvement of human health through exchange with Western medicine; (2) "Dongeuibogam" is the comprehensive summary of all the traditional medicines of North-East Asia prior to the 17th century, because it is based on a rigorous selection of 189 of the major medicinal literature sources of the region [3]; (3) it had a significant impact not only on KM after the 17th century but also on medicinal practices in other surrounding countries (e.g., China and Japan) [4]; (4) except for minor content related to superstitions, which were contemporary standards at the time of publication, most of its content is still widely used in modern KM by Korean medical doctors (KMDs); and (5) the medicinal herbs which it describes constitute many of the major herbs prescribed in KM [5]. Taken together, it seems reasonable to conclude that "Dongeuibogam" is a principal piece of KM literature and summarizes all the achievements of traditional KM. Therefore, we determined that analyzing, screening, and organizing terms describing antiaging effects (TAE) in the "Dongeuibogam" is an efficient approach for creating lists of candidate antiaging medicinal herbs (CAMH). Furthermore, pursuing this approach may help to organize preliminary data for future experimental and clinical studies on the antiaging effects of previously investigated medicinal herbs.

\section{Materials and Methods}

The present study consisted of three steps. In the first step, TAEs were screened to construct lists of TAEs. In the second step, CAMHs were screened to construct lists of CAMHs. In the last step, previous studies of CAMHs were analyzed. TAEs and CAMHs were defined by analyzing various sources of the Northeast Asian medicinal literature; TAEs in "Dongeuibogam" were defined as terms describing potency for delaying/improving specific aging symptoms that are recognized by one's human sense or others. In contrast, CAMHs were defined as medicinal herbs containing one or more TAEs in their medicinal potency [6]. Each step was performed as described in the following paragraphs.

\subsection{First Step (Figure 1): Screening TAEs Found in the "Dongeuibogam" and Establishing a List of TAEs}

2.1.1. Selection of 928 Individual Medicinal Herbs (IMH) in the "Dongeuibogam". Although there were 1,932 IMHs listed in the "Dongeuibogam," overlapping items were excluded and 928 IMHs were ultimately identified. IMH files were selected if commercially accessible; selected items were revised per $A$ New Enlarged Edition: A Translation Printed Side by Side with Original Dongeuibogam (Research team for classical Korean medical literature, 2012) prior to use.

2.1.2. Interpretation of 3,808 TAEs and Establishment of a List of Candidate TAEs. In order to meticulously interpret the TAEs of IMHs, TAEs were divided into simple descriptive units and 3,808 TAEs were identified. Each TAE was analyzed if it was related to antiaging concepts in modern science. As a result, 104 TAEs were selected as candidates. Overlapping and similar TAEs were combined, which resulted in a list of 11 subtypes.

2.1.3. Expert Survey and Establishment of the List of TAEs. Twenty-six experts were recruited for the present study. These experts were faculty members of formal institutes of KM and, concomitantly, were members of the Society of Korean Medical Classics, which consists of experts of the classical medical literature. We distributed questionnaires related to the lists of candidates and the selection criteria for TAEs in order to collect expert suggestions (period: 07.24.201408.10.2014). In the end, a TAE was selected only if more than $50 \%$ of respondents chose it and, hence, our data were narrowed to a list of 102 TAEs. The justification for setting the criteria at $50 \%$ was to retain a wider range of TAEs. The questionnaire was written by the authors and then finalized by an advisory panel consisting of basic KM researchers, clinical KM researchers, and biological science researchers $(n=6)$.

\subsection{Second Step (Figure 2): Selection of CAMHs from the "Dongeuibogam" and Establishment of the List of CAMHs}

2.2.1. Selection of Preliminary 97 CAMHs. Utilizing TAEs from the first step, 97 CAMHs were selected, which contained at least one of the TAEs.

2.2.2. Establishment of a List of 94 CAMHs. Preliminary candidates from the first selection (i.e., 97 CAMHs) were filtered into 94 CAMHs. Two were excluded because they were not from a single source and another was filtered because it was clearly based on superstition. Following this exclusion, the final list of CAMHs was established.

\subsection{Third Step (Figure 3): Preliminary Evaluation of the Anti- aging Effects of CAMHs via Analysis of Previous Studies}

2.3.1. Selection of Medicinal Herbs for Preliminary Evaluation of the Candidate Lists. Of the 94 CAMHs, the authors included medicinal herbs that are commonly used by KMDs. Following discussion with the advisory panel, 47 candidates were selected (i.e., 43 plant-derived and 4 animal-derived) for further preliminary evaluation. Ginseng Radix and honey were excluded despite their common use as medicinal ingredients because of an excessively broad range of applications.

2.3.2. Selection and Analysis of Previous Studies regarding Antiaging Effects. We searched for 47 different medicinal herbs in the previous studies and identified relevant studies concerning several major hypotheses of aging (e.g., the free radical theory [319], oxidative stress theory [320], molecular inflammation hypothesis [321, 322], neuroendocrine theory [323], wear and tear theory [324], waste accumulation theory [325], Hayflick limit theory [326], and the telomerase theory [327]). Additional studies were included after discussion with 


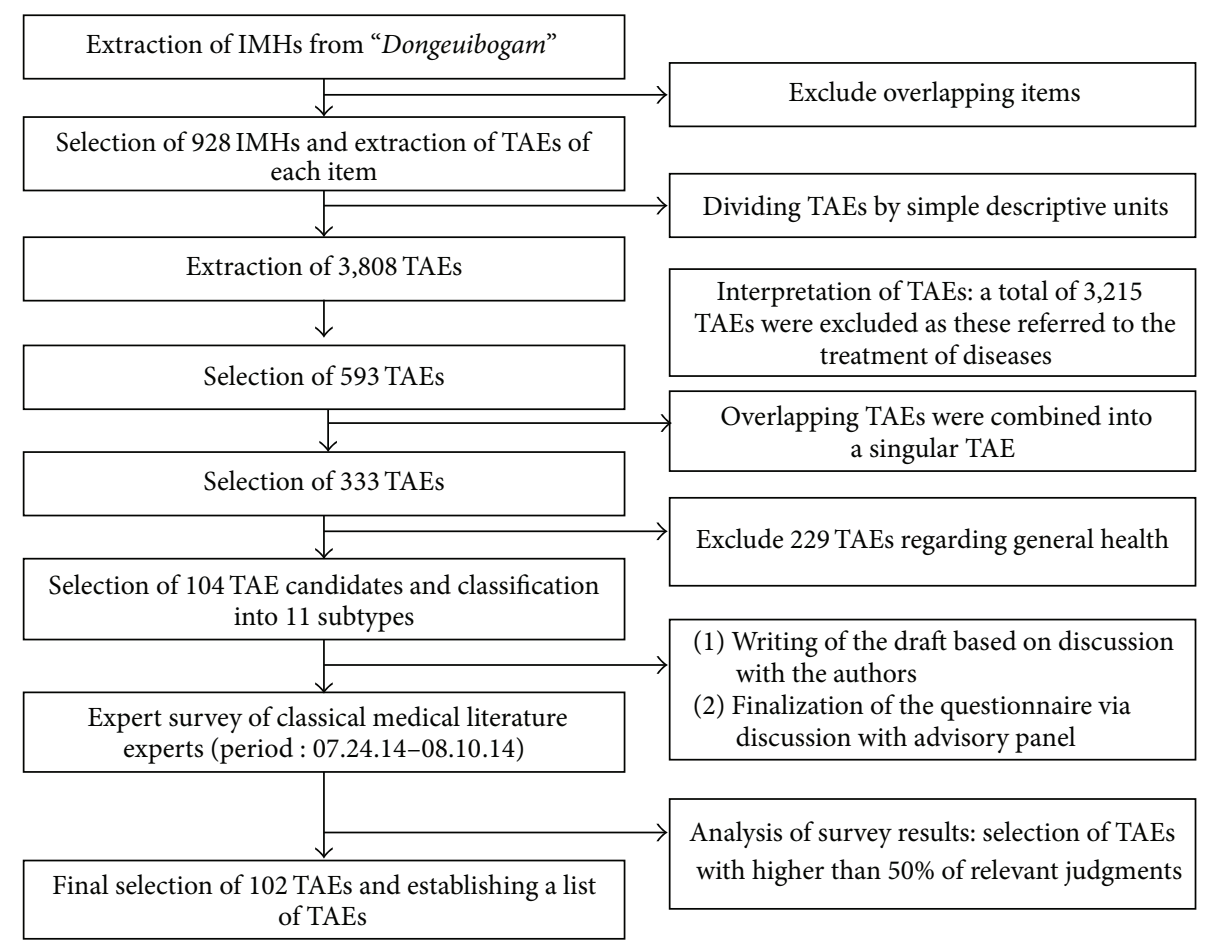

FIGURE 1: 1st research process. Screening TAEs found in the "Dongeuibogam" and establishing a list of TAEs.

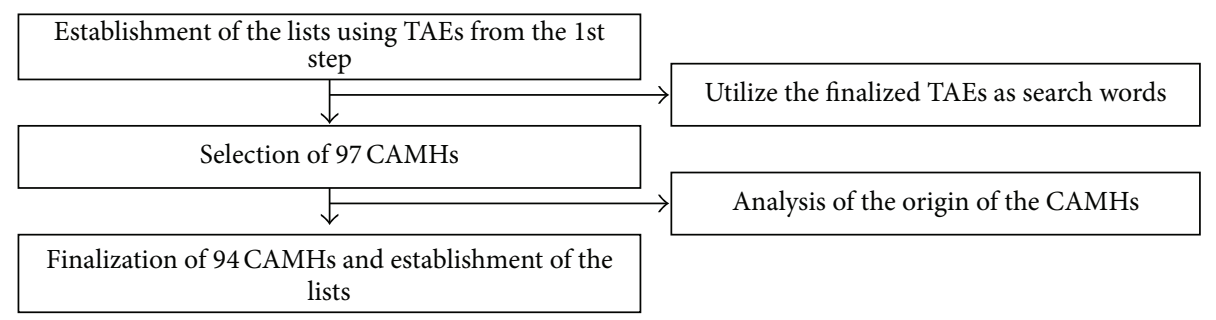

FIGURE 2: 2nd research process. Selection of CAMHs from the "Dongeuibogam" and establishment of the list of CAMHs.

the advisory panel. Next, studies were specifically divided into in vitro studies, in vivo studies, clinical studies, and reviews, and then analyzed again for research performance status.

2.3.3. Searching the Database. In addition to commonly used scientific databases (such as PubMed, Cochrane, and Scopus), Korean databases (Ndsl, Oasis, and Riss) were used since we were searching specifically for studies related to KM. The starting period for these study searches was not defined; however, July 31, 2014 was set as the final time point.

2.3.4. Searching Keywords. We used the following terms for the searches: "scientific names of CAMH + aging, age" and "names of herbal medicines of CAMH + aging, age."

\section{Results and Discussion}

3.1. List of TAEs from the "Dongeuibogam". The TAEs of 928 IMHs in the "Dongeuibogam" were divided by simple descriptive units to achieve 3,808 TAEs. In the first step, TAEs for disease treatments were excluded, resulting in 593 TAEs. Of this subset, overlapping TAEs were combined into a singular TAE list containing 333 TAEs. In the second step, 299 TAEs were excluded as they described general health. Thus, 104 TAEs specifically related to aging were selected. In order to validate the above processes, we consulted a survey of experts. Ten out of 11 respondents agreed with the validity of the first step, while one respondent disagreed $(90.9 \%$ versus $9.1 \%)$. With regard to the validity of the second step, 8 out of 10 respondents agreed ( $80 \%$ versus $20 \%$ ) (Table 1 ).

TAEs selected through the processes described above were further divided into 11 types of lists: 21 skin-related TAEs, 15 hair-related TAEs, 15 musculoskeletal TAEs, 14 sensory organ-related TAEs, 12 TAEs related to the extension of life span, 13 cognitive function-related TAEs, 5 toothrelated TAEs, 5 sexual function-related TAEs, 2 urinationrelated TAEs, 1 oral health-related TAE, and 1 respiratory function-related TAE. Classified TAEs were further assessed for proper categorization via questionnaires. In the end, depending upon the TAE, the agreement ratio for validation 


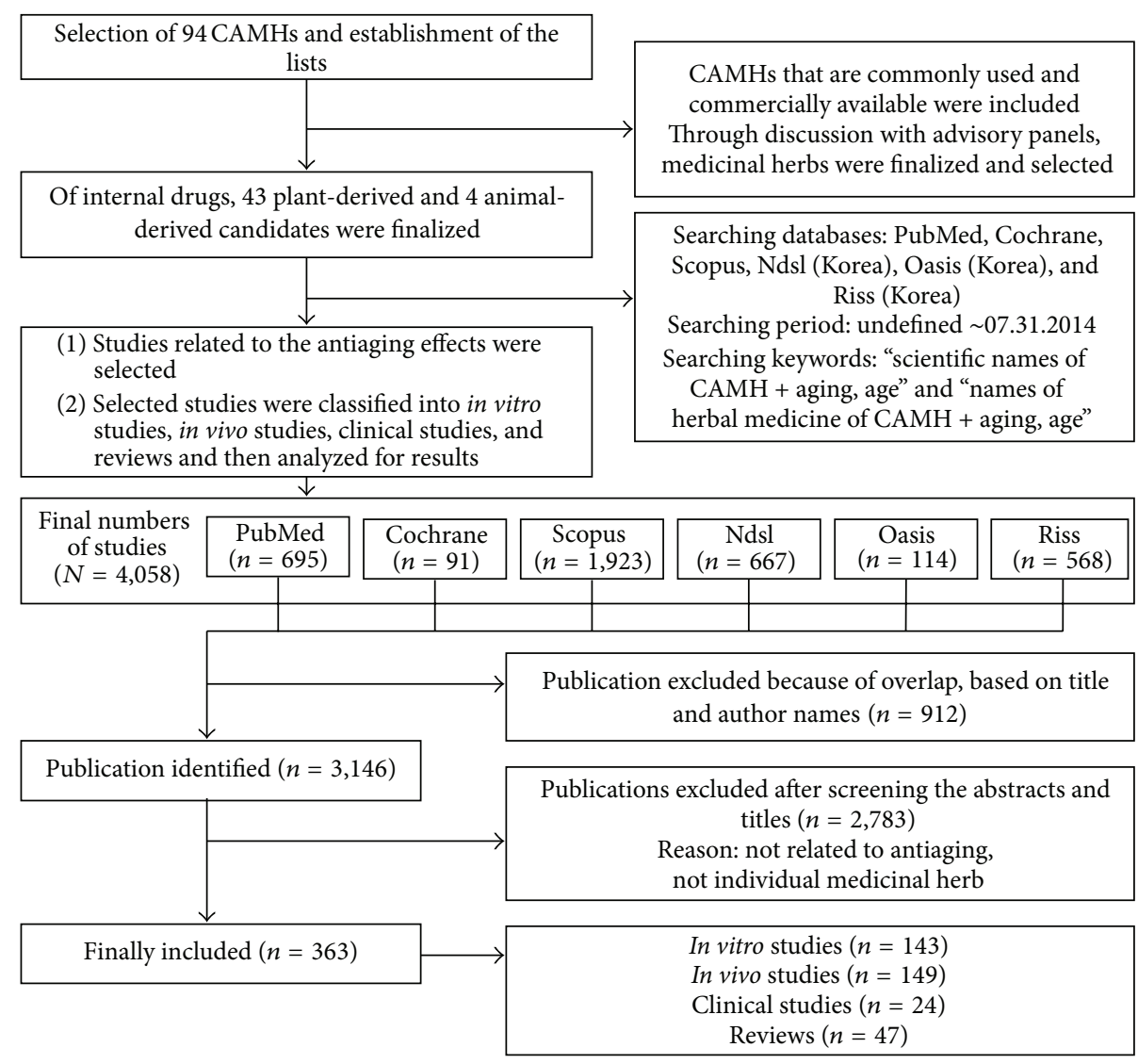

FIGURE 3: 3rd research process. Preliminary evaluation of the antiaging effects of CAMHs via analysis of previous studies.

TABLE 1: Results of survey regarding study methods.

\begin{tabular}{lccc}
\hline Question & $\begin{array}{c}\text { The number of } \\
\text { respondents for } \\
\text { "validity" }=N(\%)\end{array}$ & $\begin{array}{c}\text { The number of } \\
\text { respondents for } \\
\text { "no validity" } \\
N(\%)\end{array}$ & $\begin{array}{c}\text { Total respon- } \\
\text { dents/total } \\
\text { subjects }=N(\%)\end{array}$ \\
\hline 1 & $N=10(90.9 \%)$ & $N=1(9.1 \%)$ & $\begin{array}{c}N=11 / 26 \\
(42.3 \%)\end{array}$ \\
\hline 2 & $N=8(80 \%)$ & $N=2(20 \%)$ & $\begin{array}{c}N=8 / 26 \\
(38.5 \%)\end{array}$ \\
\hline
\end{tabular}

of each type ranged from $38.5 \%$ to $100 \%$. Two TAEs were excluded as these lists had less than $50 \%$ agreement on the validation and, therefore, 102 TAEs were finalized for further analysis. In order to avoid overlapping TAE lists, they are summarized with the lists of CAMHs as follows.

Total of 102 TAEs and 94 CAMHs Divided into 11 Subtypes (Some Items Were Medicinal Herbs Containing One or More TAEs and Were Excluded)

TAE/The Number of Respondents for "Validity" = N(\%)/ CAMHs

\section{(i) Skin-Related: 21 TAEs and 22 CAMHs}

Skin becomes glossy/9 (69.2\%)/Ginseng Radix
Removes the wrinkles even from an old man/13 (100\%)/Endocarpium Castaneae Mollissimae

Adds sheen to the face of the age/12 (92.3\%)/Suis Unguis

Adds sheen to the face/10 (76.9\%)/Leonuri Herba

Adds sheen to the face/10 (76.9\%)/Benincasae Semen

Adds sheen to the face/10 (76.9\%)/Batryticatus Bombyx

Adds sheen to the face/10 (76.9\%)/Lithar Gyrum

Improves complexion/10 (76.9\%)/Leonuri Herba

Adds sheen to the face/10 (76.9\%)/Margaritum

Removes wrinkles/12 (92.3\%)/Cervi Cornu

Fattens, whitens, and brightens the person/9 (69.2\%)/Human milk

Improves facial complexion/9 (69.2\%)/Rubi Fructus

Restores luster to a person/10 (76.9\%)/Schisandrae Fructus

Makes the facial skin smoother/10 (76.9\%)/Cervi Cornu

Makes the face look young/12 (92.3\%)/Poria Sclerotium

Adds smoothness to the face/11 (84.6\%)/Honey 
Adds sheen to the face/10 (76.9\%)/Trichosanthis Radix, Persicae Flos, and AdepsSelenarcti et Ursi

Removes wrinkles on the hands and face/12 (92.3\%)/Trichosanthis Radix

Adds sheen to the face/10 (76.9\%)/Ligustici Tenuissimi Rhizoma et Radix and Angelicae Dahuricae Radix

Makes the face younger/13 (100\%)/Atractylodis Rhizoma (Atractylodis Rhizoma Alba) and Polygonati Rhizoma

Improves facial complexion/9 (69.2\%)/PersicaeFlos, Benincasae Semen, Rubi Fructus, Cinnabaris, and Margaritum.

\section{(ii) Hair-Related: 15 TAEs and 12 CAMHs}

Reinforces the teeth and the hair/10 (76.9\%)/Zanthoxyli Pericarpium

The hair becomes black again/11 (84.6\%)/Sasemi Semen

The beard and hair do not become white/11 (84.6\%)/ Sophorae Fructus

The beard will turn black/11 (84.6\%)/Oil of the Juglandis Semen and Root of Musa basjooSieb. et Zucc

The white hair will turn black again/11 (84.6\%)/Siegesbeckia Herba

Blackens the hair/11 (84.6\%)/Mori Fructus and Ecliptae Herba

Changes the white hair to black/11 (84.6\%)/Mori Fructus

The hair will become longer/10 (76.9\%)/Adeps Selenarcti et Ursi

Makes the hair and beard black, glossy and shiny/12 (92.3\%)/Oil of the Juglandis Semen

The white beard will be dyed black/12 (92.3\%)/Juglandis Semen

Makes the hair and beard grow and changes white hair to black/13 (100\%)/Ecliptae Herba

Makes the hair grow/8 (61.5\%)/Root of Musa basjoo Sieb. et Zucc and Sasemi Semen

Makes the hair grow and become black/13 (100\%)/ Adeps Selenarcti et Ursi

Prevents the hair from becoming white/12 (92.3\%)/ Achyranthis Radix

Blackens the hair/12 (92.3\%)/Sophorae Fructus, Rehmanniae Radix (Rehmanniae Radix Crudus, Rehmanniae Radix Preparata), and Polygoni Multiflori Radix.

(iii) Musculoskeletal-Related: 14 TAEs and 23 CAMHs

Cures the weakness of legs/5 (38.5\%)/exclusion
Strengthens the bones/9 (69.2\%)/Magnetitum

Strengthens the muscles and bones/9 (69.2\%)/Acanthopanacis Cortex

Makes the body feel light/11 (84.6\%)/ChrysanthemiFlos, Euryales Semen, Lycii Fructus, Colophonum, Nelumbinis Semen, Acanthopanacis Cortex, Rehmanniae Radix (Rehmanniae Radix Crudus, Rehmanniae Radix Preparata), Acori Gramineri Rhizoma, Asparagi Tuber, Atractylodis Rhizoma (Atractylodis Rhizoma Alba), Cuscutae Semen, Pini Koraiensis Semen, Sasemi Semen, Polygonati Rhizoma

Strengthens the muscles and bones/9 (69.2\%)/Siegesbeckia Herba

Strengthens the muscles and bones/9 (69.2\%)/Chaenomelis Fructus

Strengthens the muscles and bones/9 (69.2\%)/ Eucommiae Cortex

Strengthens the muscles/8 (61.5\%)/Animalis Nervus; exclusion

Strengthens the power/7 (53.8\%)/Rubi Fructus

Strengthens the muscles/7 (53.8\%)/Chaenomelis Fructus

Helps one gain power/7 (53.8\%)/Epimedii Herba, Rehmanniae Radix (Rehmanniae Radix Crudus, Rehmanniae Radix Preparata)

Gives strength/7 (53.8\%)/Rubi Fructus

Strengthens the muscles and bones/8 (61.5\%)/Chrysanthemi Flos, Cervi Parvum Cornu, Schisandrae Fructus

Strengthens the muscles/7 (53.8\%)/Polygoni Multiflori Radix

Treats a general lack of enthusiasm/7 (53.8\%)/Lycii Fructus.

(iv) Related to the 5 Sensory Organs: 14 TAEs and 47 CAMHs

Enhances eyesight/9 (69.2\%)/Brassica Rapae Radix Seu Folium, Natrii Chloridum, Galla Rhois, Naemorhedi Jecur

Enhances eyesight and hearing abilities/10 (76.9\%)/ Acori Gramineri Rhizoma

Enhances eyesight/9 (69.2\%)/Chrysanthemi Flos, Canitis Fel, Cassiae Leaves, Cassiae Semen, Azuritum, Sophorae Fructus, Malachitum, Brassica Rapae Radix Seu Folium, Equiseti Herba, Rubi Fructus, Serpentis Periostracum, Haliotidis Concha, Asiasari Radix et Rhizoma, NatriiChloridum, GallaRhois, BovisJecur, Human milk, Suis Testis, Gapsellae Bursa-pastoris Semen, Citrus Unshius Pericarpium, Xanthii Fructus, Naemorhedi Jecur, Sal, AtractylodisRhizoma AtractylodisRhizoma Alba, LepiJecur, Cuscutae Semen, Phellodendri Cortex, and Coptidis Rhizoma 
Enhances eyesight and cures weak vision/9 (69.2\%)/ Sophorae Fructus, Vespertilii Excrementum, and Naemorhedi Jecur

Treats blurred vision/9 (69.2\%)/Viticis Fructus

Treats blurred vision/9 (69.2\%)/Cicadae Periostracum

Treats blurred vision/9 (69.2\%)/Galli Mas Os Nigri Fel

The vision is unclear/7 (53.8\%)/Lutrae Fel

Brighten the eyes/9 (69.2\%)/Siegesbeckia Herba

Enhances the vision/9 (69.2\%)/Citrus Unshius Pericarpium

Improves the eyesight/9 (69.2\%)/Serpentis Periostracum and Human milk

Cures the weak vision/9 (69.2\%)/Mirabilitum

Cures the weak vision/9 (69.2\%)/Lepi Jecur

Makes the hearing and the vision better/10 (76.9\%)/Euryales Semen.

\section{(v) Related to Extension of Life Span: 12 TAEs and 37 CAMHs}

Lengthens the life/13 (100\%)/Poria Sclerotium

Keeps one young/13 (100\%)/Chrysanthemi Flos, Euryales Semen, Poria Sclerotium, Nelumbinis Semen, and Acanthopanacis Cortex

Elongates the life/13 (100\%)/Atractylodis Rhizoma (Atractylodis Rhizoma Alba)

Keeps one young/12 (92.3\%)/Euryales Semen

Keeps one young/13 (100\%)/Cervi Parvum Cornu

Ensures a long life/12 (92.3\%)/Nelumbinis Semen

Ensures a long life/12 (92.3\%)/Lycii Fructus

Keeps one young/13 (100\%)/Cervi Parvum Cornu, Mori Fructus, Colophonum, Rehmanniae Radix (Rehmanniae Radix Crudus, Rehmanniae Radix Preparata), Acori Gramineri Rhizoma, Atractylodis Rhizoma (Atractylodis Rhizoma Alba), Polygoni Multiflori Radix, Pini Koraiensis Semen, Sasemi Semen, and Polygonati Rhizoma

Elongates the life/12 (92.3\%)/Thujae Orientalis Folium, Poria Sclerotium, Colophonum, Nelumbinis Semen, Acanthopanacis Cortex, Acori Gramineri Rhizoma, Asparagi Tuber, Atractylodis Rhizoma (Atractylodis Rhizoma Alba), Cuscutae Semen, Polygoni Multiflori Radix, Pini Koraiensis Semen, and Sasemi Semen

Elongates the life/13 (100\%)/Human milk

Elongates the life/13 (100\%)/Chrysanthemi Flos, Thujae Orientalis Folium, Acori Gramineri Rhizoma, Atractylodis Rhizoma (Atractylodis Rhizoma Alba), and Polygoni Multiflori Radix
Ensures a long life/12 (92.3\%)/Euryales Semen, Sophorae Fructus, Atractylodis Rhizoma (Atractylodis Rhizoma Alba), Sasemi Semen, and Multae Flores; exclusion.

(vi) Cognitive Functions-Related: 12 TAEs and 9 CAMHs

Cures forgetfulness/10 (76.9\%)/Calculus, Polygalae Radix, Hominis Placenta, Suis Cordis, and Aranea Ventricosa Cobwe (exclusion)

Cures forgetfulness/10 (76.9\%)/Ginseng Radix

Makes one smart/9 (69.2\%)/Acori Gramineri Rhizoma

Cures forgetfulness/10 (76.9\%)/Hoelen cum Radix

Cures forgetfulness/10 (76.9\%)/Aranea Ventricosa Cobwe; exclusion

Nurtures the spirit/9 (69.2\%)/Nelumbinis Semen

Makes one smart/9 (69.2\%)/Polygalae Radix, Alpiniae Oxyphyllae Fructus, and Ginseng Radix

Makes one smart/9 (69.2\%)/Acori Gramineri Rhizoma

Makes one smart/9 (69.2\%)/Polygalae Radix

Makes one smart/8 (61.5\%)/Acori Gramineri Rhizoma

Cures forgetfulness/10 (76.9\%)/Calculus

Makes one's mind feel cool/8 (61.5\%)/Nelumbinis Semen

Cools the head and eyes/6 (46.2\%)/exclusion.

\section{(vii) Tooth-Related: 5 TAEs and 9 CAMHs}

Reinforces the teeth and the hair/11 (84.6\%)/Zanthoxyli Pericarpium

Reinforces the teeth/9 (69.2\%)/Bovis Dens

Reinforces the teeth/9 (69.2\%)/Drynariae Rhizoma, Sophorae Fructus, Cervi Parvum Cornu, Natrii Chloridum, and Tribuli Fructus

Strengthens the teeth/9 (69.2\%)/Ashes of a sheep's Tibia, Sal

Stimulates the growth of teeth/8 (61.5\%)/Cervi Parvum Cornu.

(viii) Related to Sexual Functions: 5 TAEs and 7 CAMHs

Strengthens the sexual function/7 (53.8\%)/Passeris Caro

Cures the impotence/9 (69.2\%)/Bombyxmori L.

Strengthens the sexual function/8 (61.5\%)/Passeris Caro

Cures the impotence/9 (69.2\%)/Canitis Penis et Testis, Rubi Fructus, Otariae Testis et Penis, Achyranthis Radix, Epimedii Herba 
Cures the impotence/9 (69.2\%)/Canitis Penis et Testis.

The following 4 TAEs are for disease treatment. But they were selected as TAEs because they have the words, "the elderly."

(ix) Urination-Related: 2 TAEs and 2 CAMHs

Cures the abnormal urination of the elderly/8 $(61.5 \%) / C o r n i$ Fructus

Cures the enuresis of the elderly/8 (61.5\%)/Achyranthis Radix.

\section{(x) Oral Health-Related: 1 TAE and 1 CAMH}

Cures the canker sore of the elderly/8 (61.5\%)/Human milk.

\section{(xi) Respiratory Function-Related: 1 TAE and 1 CAMH}

Cures the chronic cough of the elderly/8 (61.5\%)/ Armeniacae Semen.

3.2. Lists of CAMHs in the "Dongeuibogam". Ninety-seven medicinal herbs associated with at least one TAE were selected from the "Dongeuibogam." Among these herbs, three items were excluded because "Multae Flores" and "Animalis Nervus" stand for various flowers and multiple animals' muscles, respectively. In addition, the unreasonable item, "Aranea ventricosa cobweb," was also excluded. Therefore, $94 \mathrm{CAMHs}$ were finally selected. These candidates were divided into categories for either internal or external use, and were then subdivided into plant-derived, animal-derived, and mineral-derived medicinal herbs as follows.

CAMHs were Divided into Categories for Either Internal or External Use, Subdivided into Plant-Derived, Animal-Derived, and Mineral-Derived Medicinal Herbs

\section{(i) 69 CAMHs for Internal Use}

45 Plant-Derived Medicinal Herbs. Acanthopanacis Cortex/ Achyranthis Radix/Acori Gramineri Rhizoma/Alpiniae Oxyphyllae Fructus/Armeniacae Semen/Asiasari Radix et Rhizoma/Asparagi Tuber/Atractylodis Rhizoma (Atractylodis Rhizoma Alba)/Brassica Rapae Radix Seu Folium/Cassiae Leaves/Chaenomelis Fructus/Chestnut/Chrysanthemi Flos/ Citrus Unshius Pericarpium/Colophonum/Coptidis Rhizoma/Corni Fructus/Cuscutae Semen/Ecliptae Herba/Epimedii Herba/Equiseti Herba/Eucommiae Cortex/Euryales Semen/Gapsellae Bursa-pastoris Semen/Ginseng Radix/ Hoelen cum Radix/Lycii Fructus/Mori Fructus/Nelumbinis Semen/Persicae Flos/Phellodendri Cortex/Pini Koraiensis Semen/Polygalae Radix/Polygonati Rhizoma/Polygoni Multiflori Radix/Poria Sclerotium/Rehmanniae Radix (Rehmanniae Radix Crudus, Rehmanniae Radix Preparata)/Rubi Fructus/Sasemi Semen/Schisandrae Fructus/Siegesbeckia
Herba/Sophorae Fructus/Thujae Orientalis Folium/Viticis Fructus/Xanthii Fructus.

20 Animal-Derived Medicinal Herbs. Bombyx mori L./Bovis Calculus/Bovis Jecur/Canitis Fel/Canitis Penis et Testis/ Cervi Cornu/Cervi Parvum Cornu/Cicadae Periostracum/ Haliotidis Concha/Hominis Placenta/Honey/Human milk/ Lepi Jecur/Naemorhedi Jecur/Otariae Testis et Penis/Passeris Caro/Serpentis Periostracum/Suis Cordis/Suis Testis/ Vespertilii Excrementum.

4 Mineral-Derived Medicinal Herbs. Azuritum/Cinnabaris/ Magnetitum/Malachitum.

\section{(ii) 25 CAMHs for External Use}

13 Plant-Derived Medicinal Herbs. Angelicae Dahuricae Radix/Benincasae Semen/Cassiae Semen/Drynariae Rhizoma/Endocarpium Castaneae Mollissimae/Galla Rhois/ Juglandis Semen (Oil of the Juglandis Semen)/Leonuri Herba/Ligustici Tenuissimi Rhizoma et Radix/Root of Musa basjoo Sieb. et Zucc/Tribuli Fructus/Trichosanthis Radix/ Zanthoxyli Pericarpium.

7 Animal-Derived Medicinal Herbs. Adeps Selenarcti et Ursi/Batryticatus Bombyx/Bovis Dens/Galli Mas Os Nigri Fel/Lutrae Fel/Suis Unguis/Tibia of a sheep's ashes.

5 Mineral-Derived Medicinal Herbs. Lithar Gyrum/Margaritum/Natrii Chloridum/Natrii Sulfas/Sal.

Lastly, these were classified utilizing TAEs as well (since there were medicinal herbs possessing one or more TAEs, some items overlapped; as explained previously).

3.3. Preliminary Evaluation of the Antiaging Effects of CAMHs via Analysis of Previous Studies. Through discussion with advisory panels, the authors selected 47 kinds of CAMHs (i.e., 43 plant-derived kinds and 4 animal-derived kinds) that are commercially available and widely utilized by KMDs. A total of 3,146 studies of 47 CAMHs were found; of these, 363 studies were concerned with antiaging effects, resulting in an average of 7.7 publications per candidate herb (Table 2).

As depicted in Table 2, 43 kinds of CAMHs were studied and their antiaging activity was corroborated by more than one research study (except Equiseti Herba, Gapsellae Bursa-pastoris Semen, Poria Sclerotium, Siegesbeckia Herba, Sophorae Fructus, and Viticis Fructus). Among these publications, there were medicinal herbs assessed in multiple studies with various references to their potency against aging. For instance, there were 58 publications found for Lycii Fructus, 25 for Epimedii Herba, 24 for Polygoni Multiflori Radix, and 23 for Mori Fructus. In contrast, only one relevant study each was found for Euryales Semen, Thujae Orientalis Folium, and Xanthii Fructus. However, regardless of the number of previous studies, the finalized list of CAMHs should be investigated for their antiaging potency because these CAMHs were carefully selected by TAE criteria that were agreed upon by the consultation and agreement of experts. 


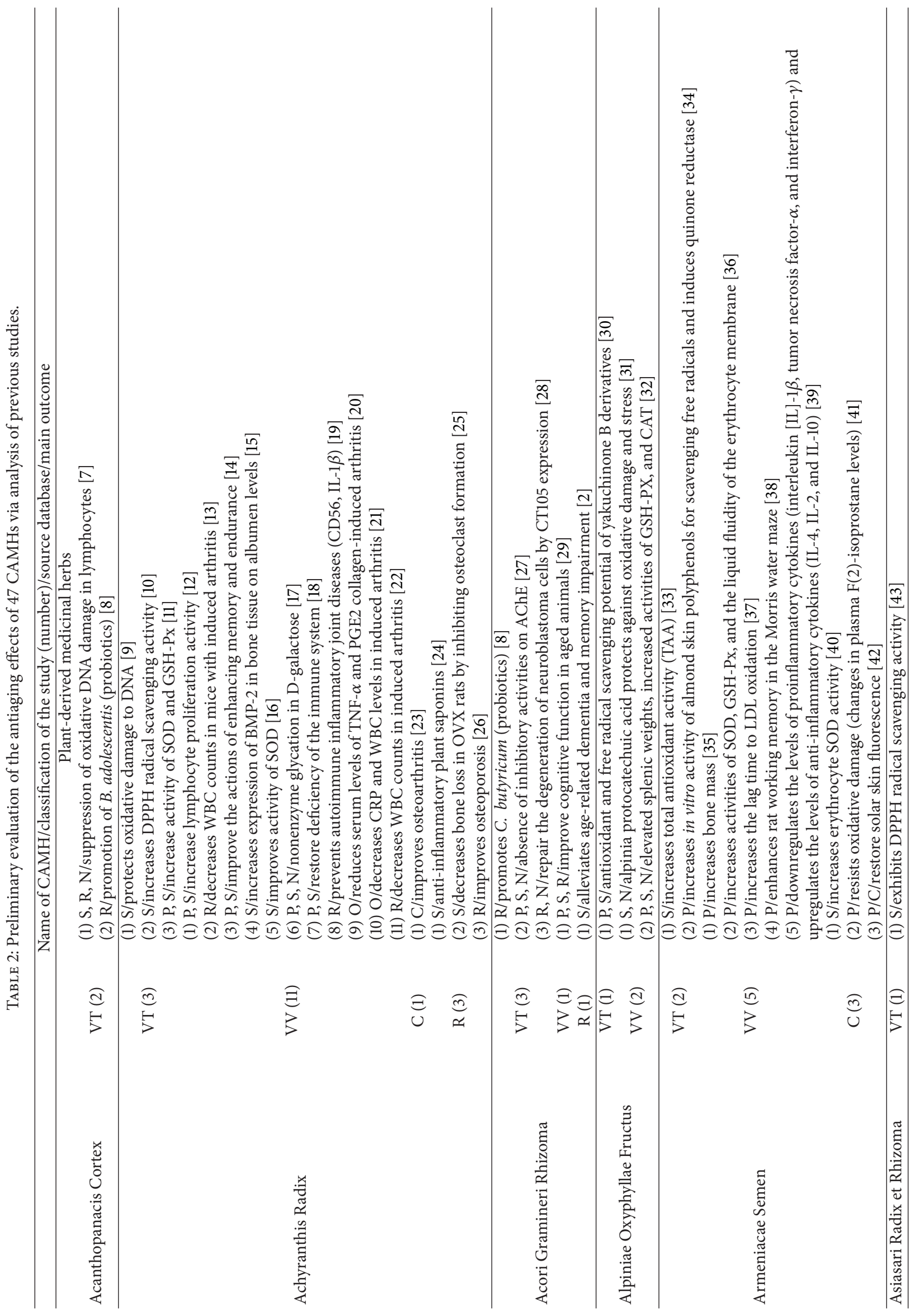




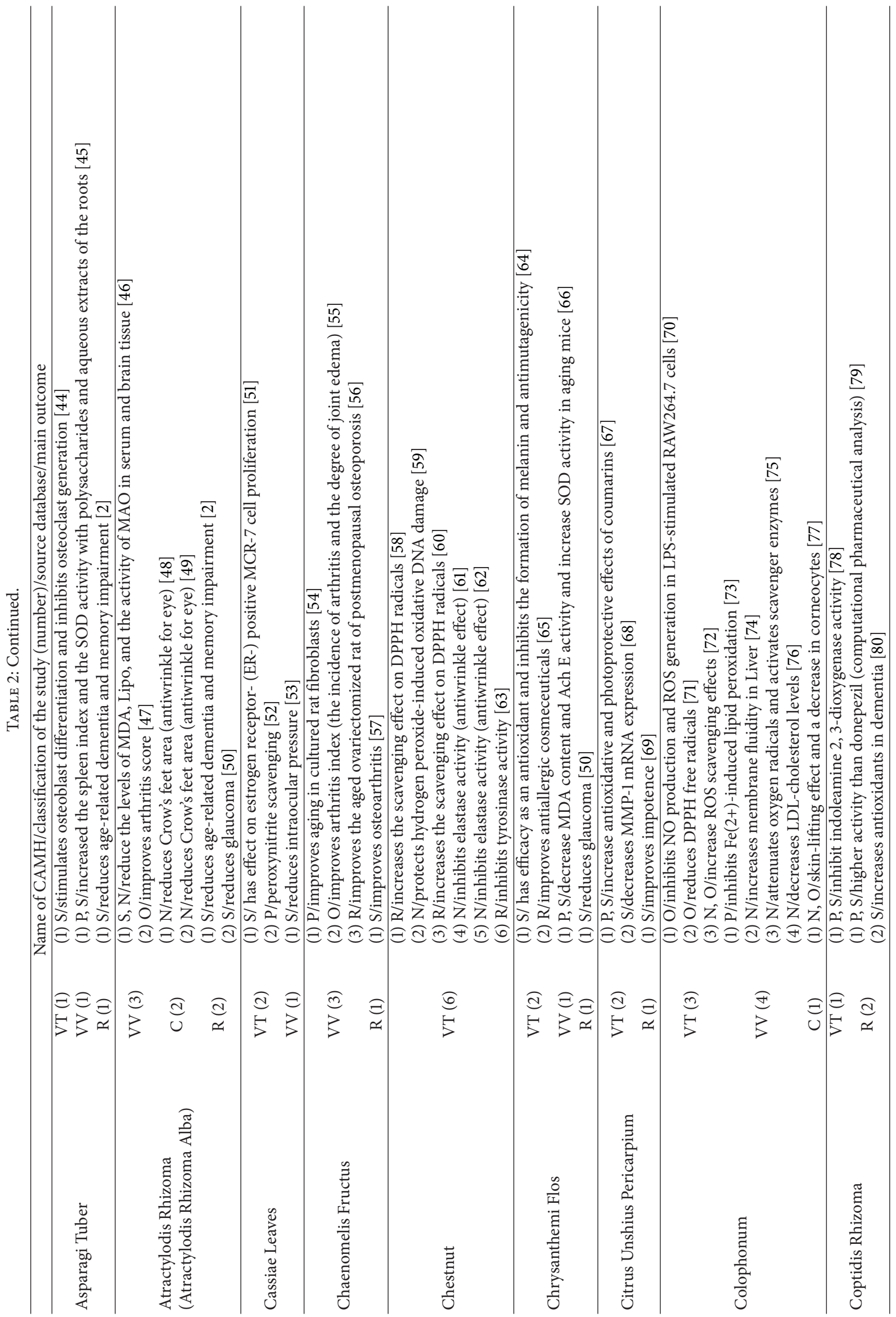




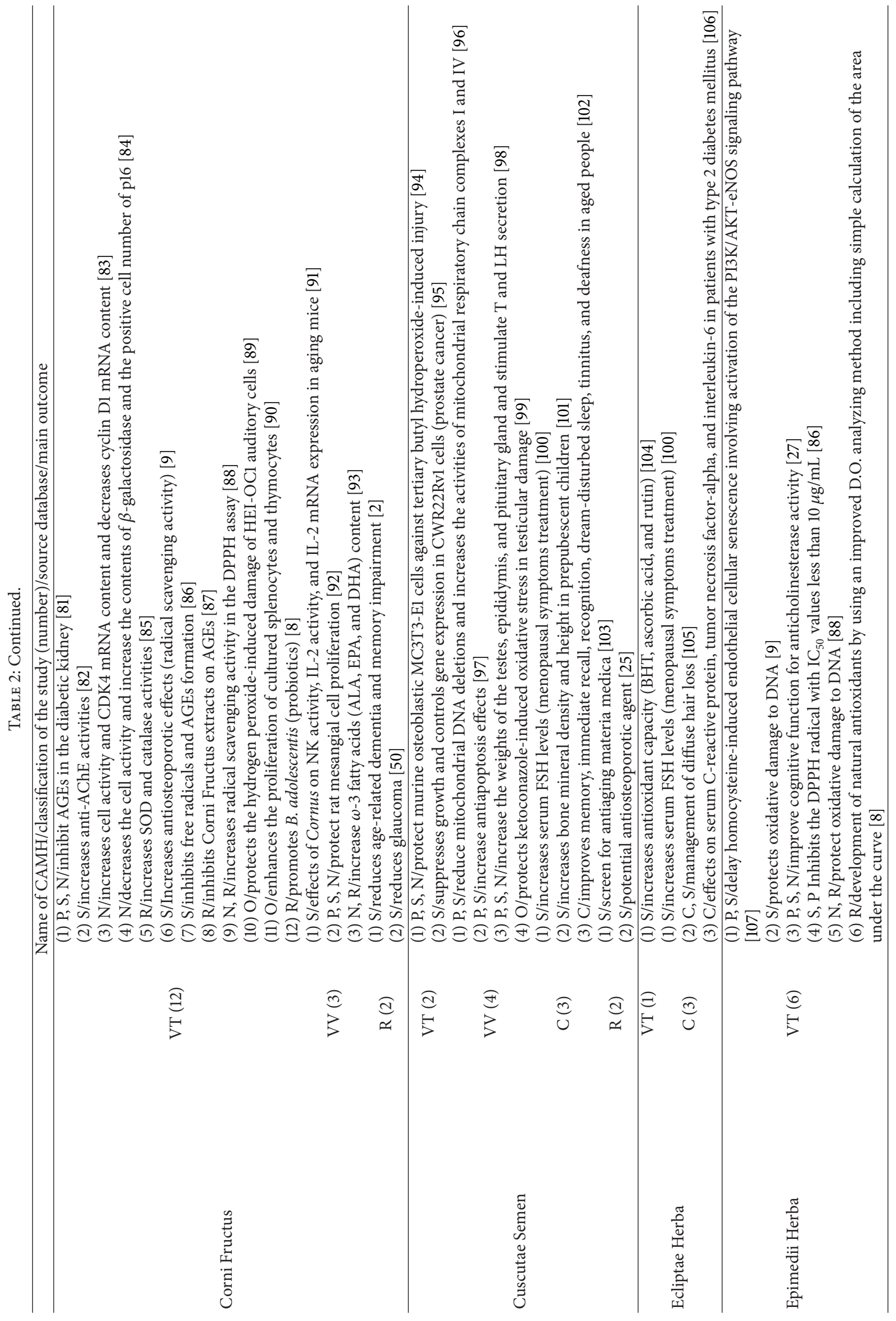




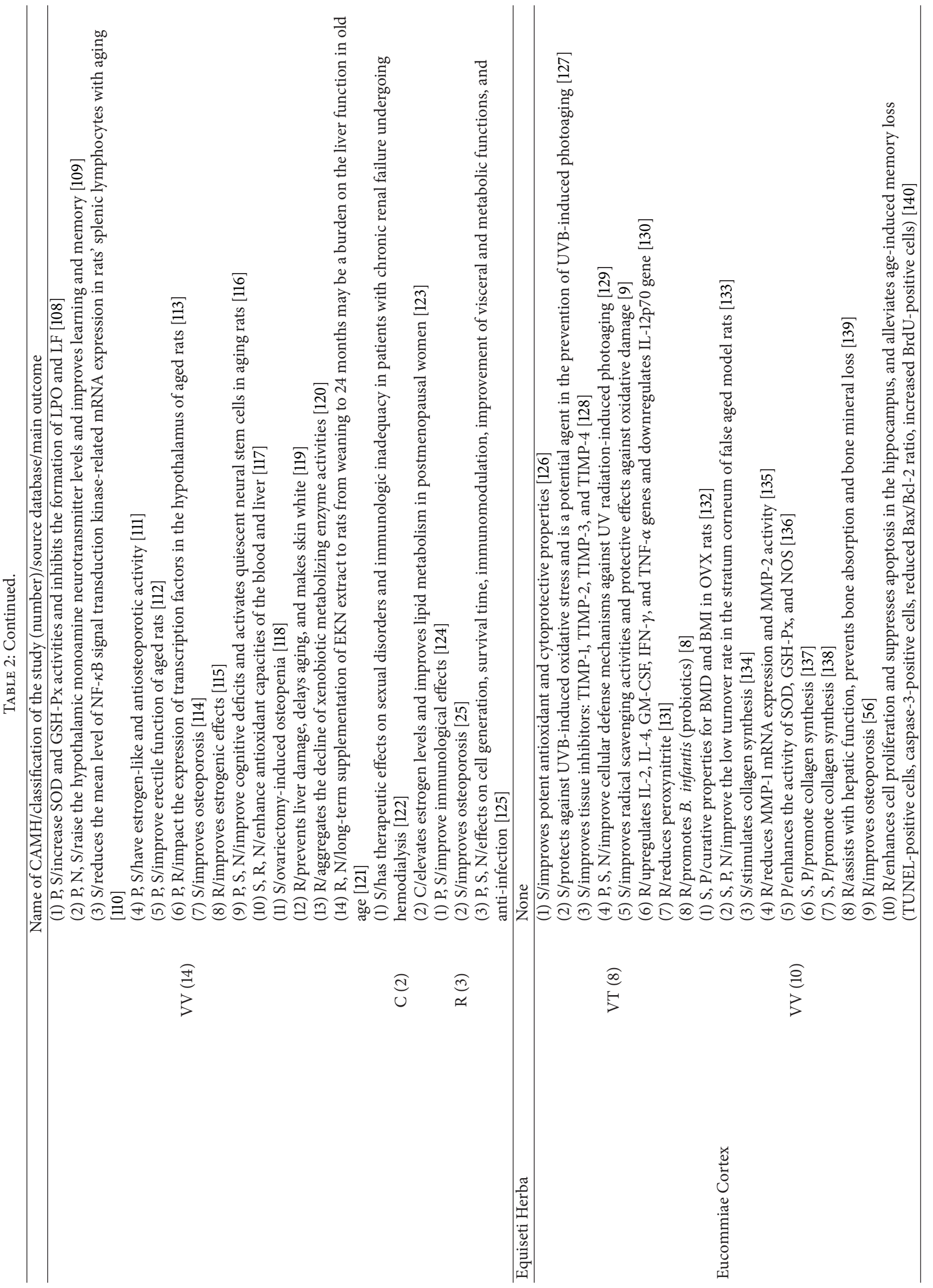




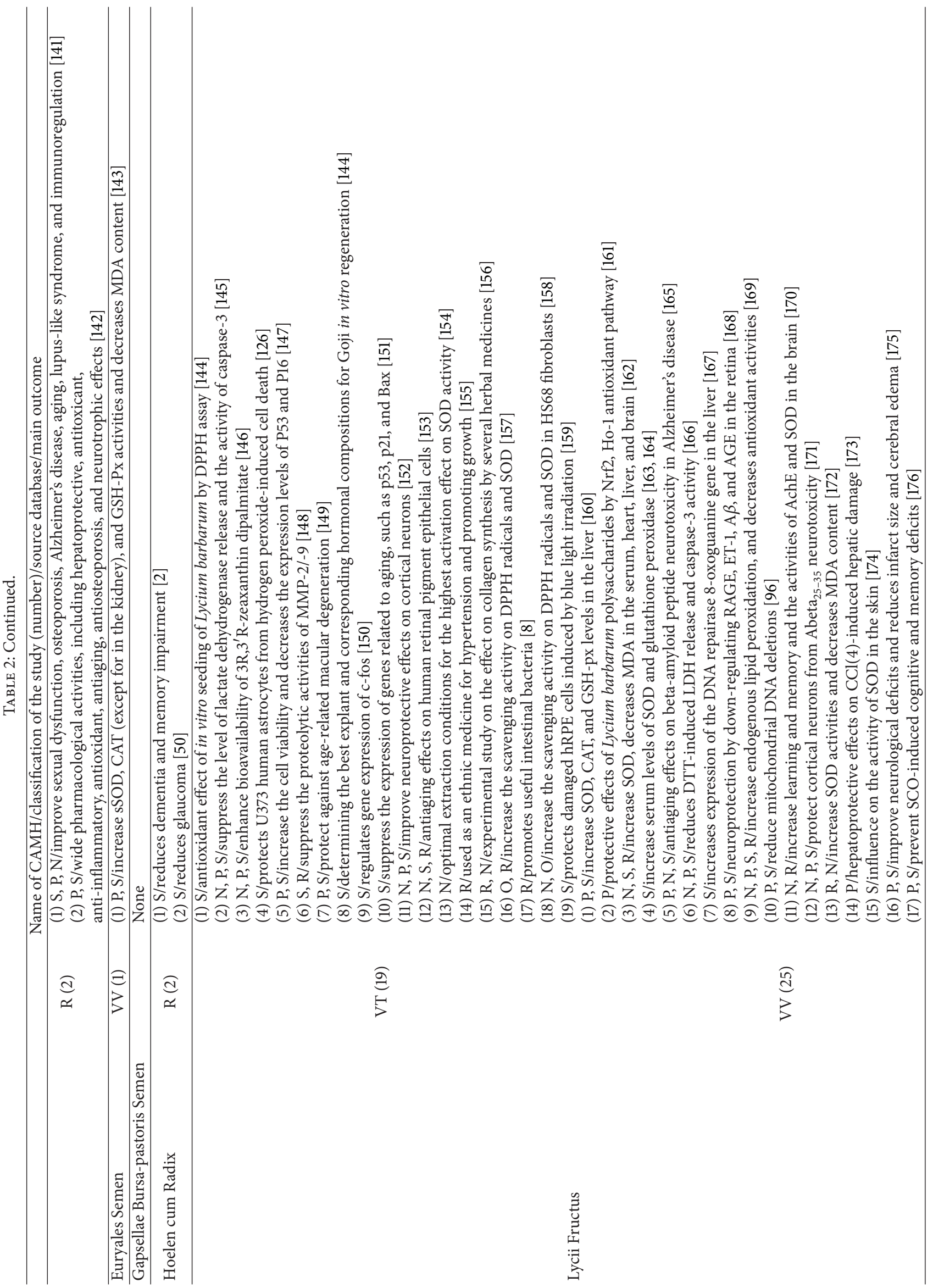




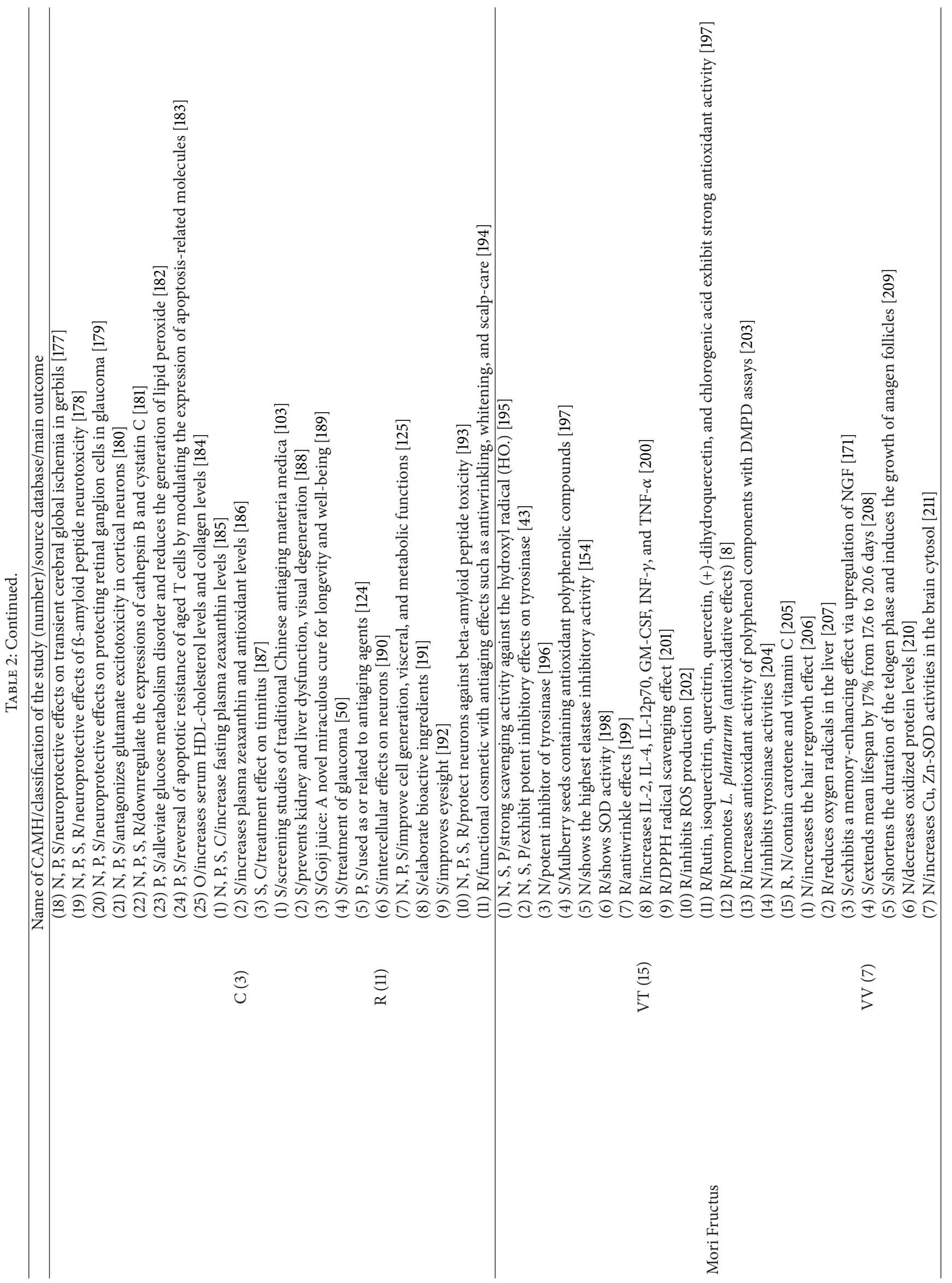




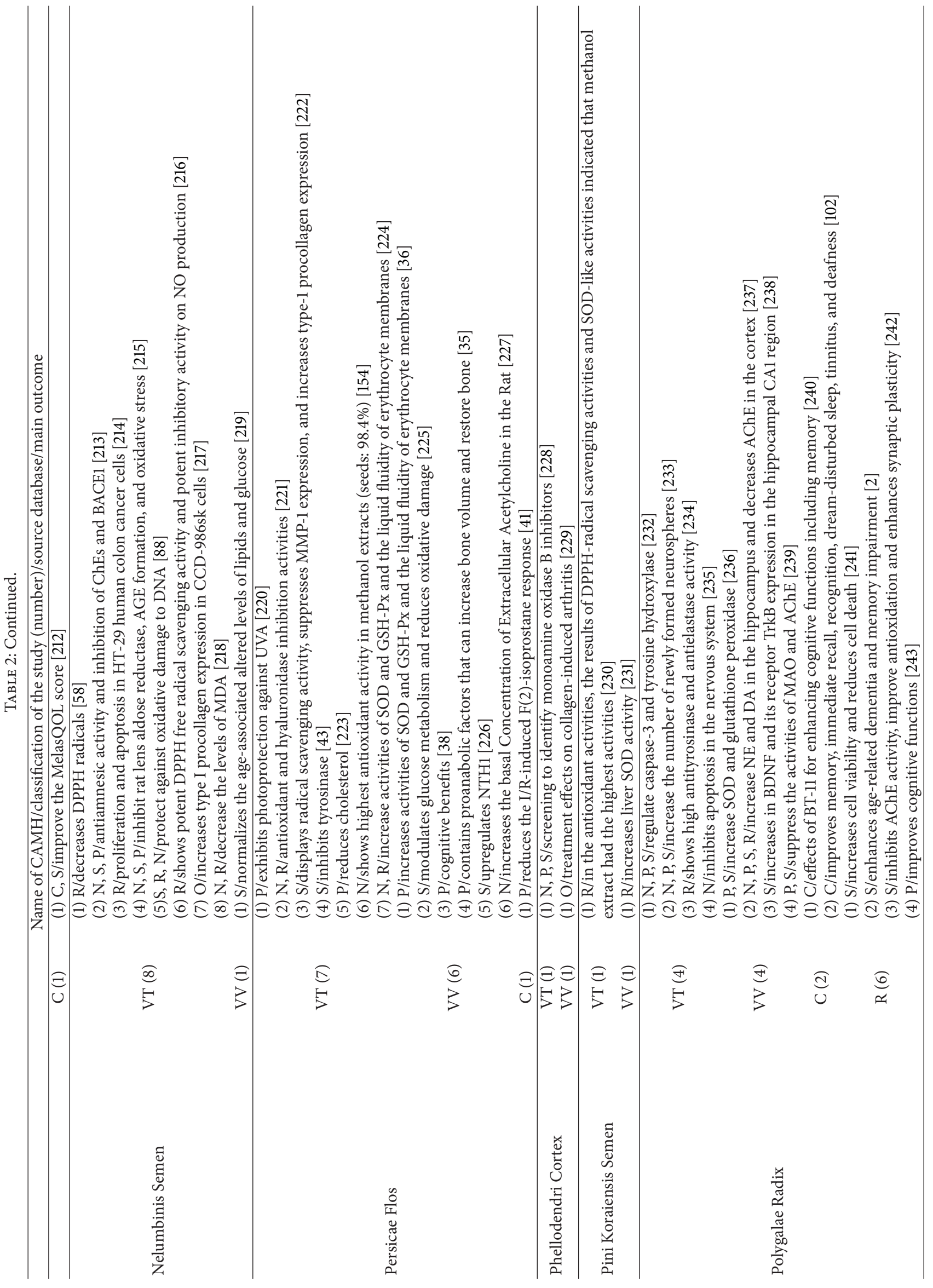




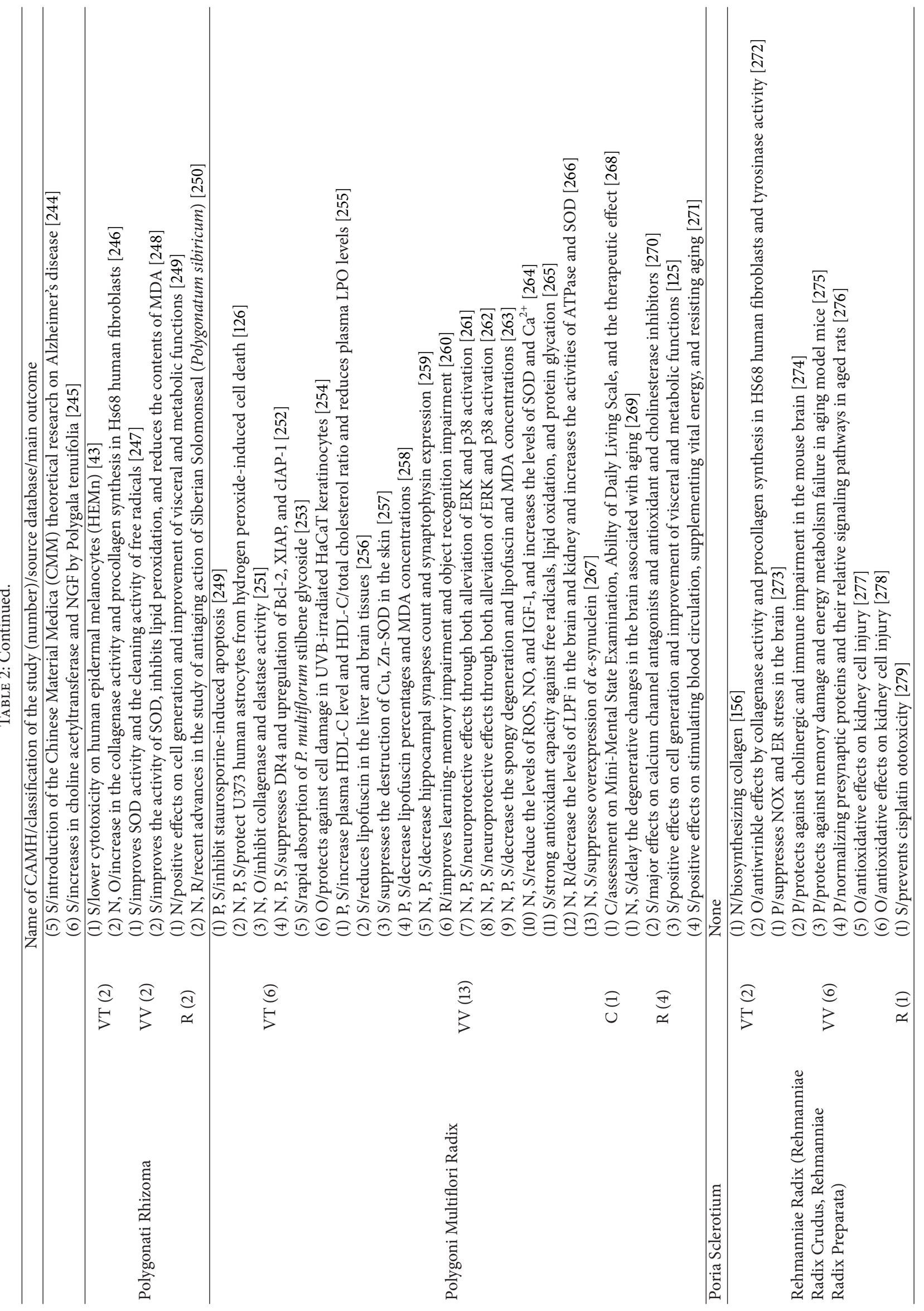




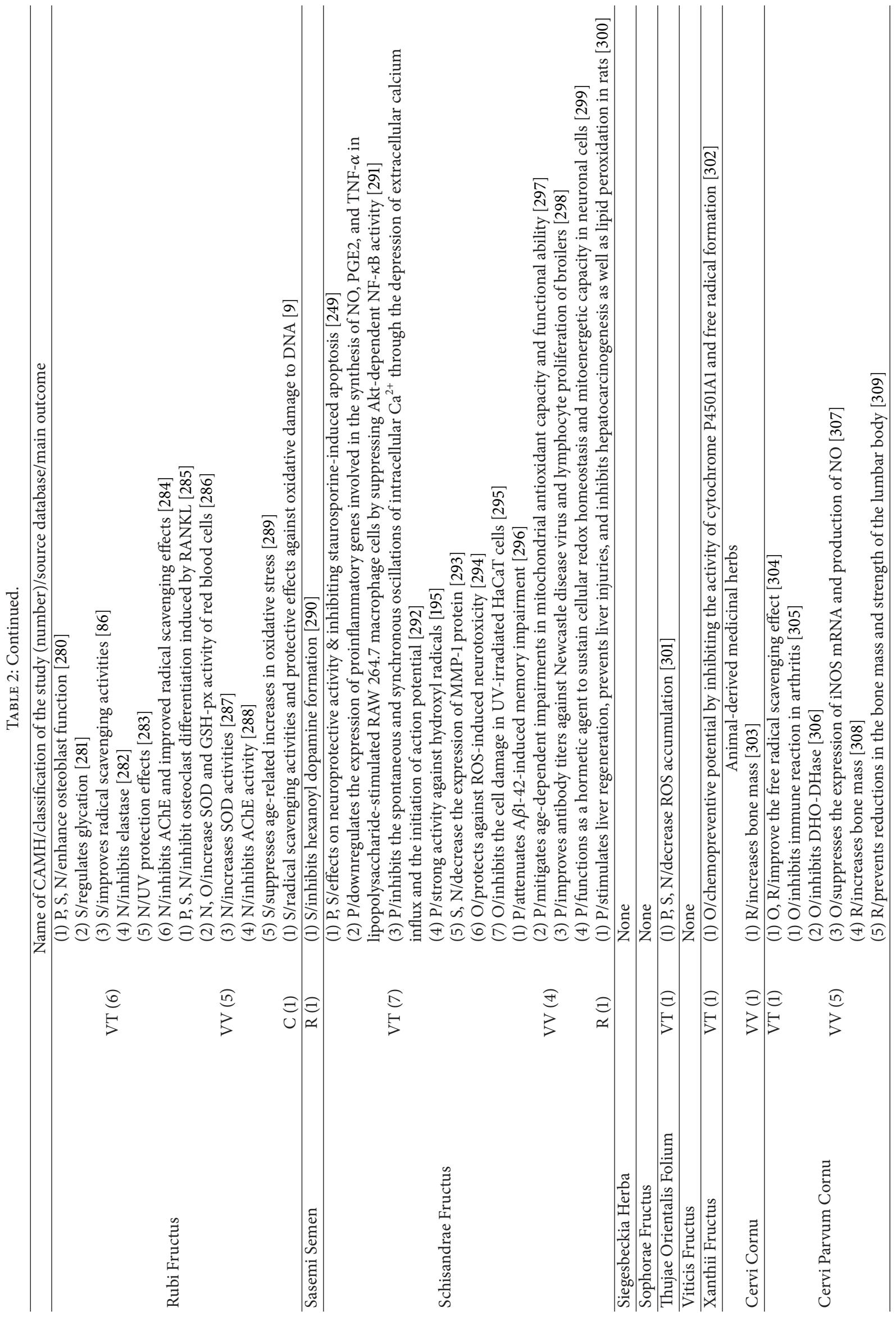




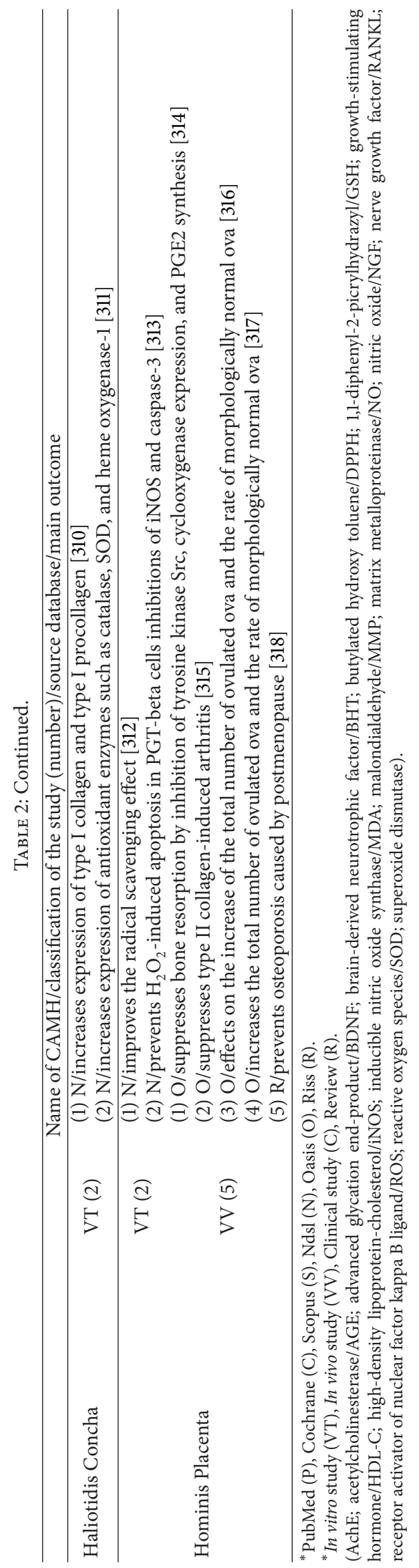


Since the present study was performed with a focus on the selection and cataloging of an entire candidate group of antiaging medicinal herbs written about in the "Dongeuibogam," the characteristics of each medicinal herb were not analyzed in detail during both the discovery processes from the classical Korean medical literature and the analysis processes of preceding studies. This constitutes a limitation of the present study but is also an advantage because the scope of this study is comprehensive. This part will be included in a follow-up study on the verification of the antiaging effects of each CAMH.

Furthermore, additional investigation is warranted for the "Compound formulae" (mixture of medicinal herbs) identified in "Dongeuibogam" as an expansion of the present study that limited putative candidates to IMHs.

\section{Conclusions}

In the present study, we finally selected $47 \mathrm{CAMHs}$ from the "Dongeuibogam" and reviewed the results of previous studies regarding antiaging effects in order to provide a comprehensive list of Korean medicinal herbs that may harbor antiaging potential. Even though further investigations are needed in regard to the medicinal herbs included in these lists, the present study may be an important step towards the development of experimental and clinical studies with the aim of discovering new drugs or novel antiaging constituents.

\section{Conflict of Interests}

The authors declare that there are no conflict of interests regarding the publication of this paper.

\section{Acknowledgment}

This research was supported by the Basic Science Research Program of the National Research Foundation of Korea (NRF) funded by the Ministry of Education (NRF2013R1A1A2060970).

\section{References}

[1] L. Zhang, Y. Li, X. Guo et al., "Text mining of the classical medical literature for medicines that show potential in diabetic nephropathy," Evidence-Based Complementary and Alternative Medicine, vol. 2014, Article ID 189125, 12 pages, 2014.

[2] B. H. May, C. Lu, L. Bennett, H. M. Hügel, and C. C. L. Xue, "Evaluating the traditional Chinese literature for herbal formulae and individual herbs used for age-related dementia and memory impairment," Biogerontology, vol. 13, no. 3, pp. 299-312, 2012.

[3] K. R. Park, A bibliographic study on donguibogam [Ph.D. thesis], Graduate School, Chonnam National University, 2009.

[4] O. Kwon, W. Cha, S. Park, J. Oh, and S. Ahn, “The appropriation of donguibogam and bencao gangmu and the shaping of distinctive Korean medicine in the late joseon dynasty," Korean Journal of Oriental Medicine, vol. 17, no. 3, pp. 17-24, 2011.
[5] N. Kim, "The significance of Dongeuibogam registration and its modern application," Korean Journal of Oriental Medicine, vol. 15, no. 1, article 14, 2009.

[6] D.-W. Lee and J.-U. Baek, "A study on analyzing the terms describing anti-aging effects in Dongeuibogam to propose the methodology for selecting medicinal herbs related to anti-aging effects," Journal of Korean Medical Classics, vol. 27, no. 2, pp. 2548, 2014.

[7] C.-K. Kim and S.-K. Park, "Effect of Acanthopanax sessiliflorus extracts on stress response and aging in Caenorhabditis elegans," Food Science and Technology Research, vol. 19, no. 3, pp. 439444, 2013.

[8] D. H. Kim, Search for antioxidants from natural products and their growth promoting effects on intestinal useful bacteria [M.S. thesis], Graduate School, Yosu National University, 2002.

[9] S. Choi, D. Yim, and S. Lee, "Radical scavenging activities and protective effects against oxidative damage to DNA of extracts from medicinal plants with known osteoprotective effects," Korean Journal of Pharmacognosy, vol. 40, no. 2, pp. 143-149, 2009.

[10] M. K. Na, R. B. An, W. Y. Jin et al., "Antioxidant effects of plant extracts on free radicals and lipid peroxidation," Natural Product Sciences, vol. 9, no. 4, pp. 226-231, 2003.

[11] X. P. Li, "Experimental study on anti-senility of the 4 famous Chinese herbs produced in Huaiqing area," Chinese Journal of Modern Developments in Traditional Medicine, vol. 11, no. 8, pp. 486-454, 1991.

[12] Q. Chen, Z. Liu, and J.-H. He, "Achyranthes bidentata polysaccharide enhances immune response in weaned piglets," Immunopharmacology and Immunotoxicology, vol. 31, no. 2, pp. 253-260, 2009.

[13] W. S. Do, K. H. Kim, and K. S. Kim, "Cortex Pumilae, Ramulus Cinnamomum, Radix Achyranthis, Apitoxin, Calculus Bovis, Fel Ursi, Moschus compound in mice with lipopolysaccharide induced arthritis," The Journal of Korean Acupuncture and Moxibustion Society, vol. 18, no. 1, 2001.

[14] A. Ma and H. Guo, "Effect of radix Achyranthis bidentatae on memory and endurance," Journal of Chinese Medicinal Materials, vol. 21, no. 12, pp. 624-626, 1998.

[15] Y. Li, R.-H. Zhang, X.-F. Zhu, Y. Cai, and F. Huang, "Effects of benefiting-bone capsule on expression of bone morphogenetic protein-2 in bone tissue of the ovariectomized rats," Chinese Journal of Clinical Rehabilitation, vol. 10, no. 3, pp. 190-192, 2006.

[16] Q. Xu, S.-H. Yang, L.-W. Zhao, and Z.-H. Chen, "Influences of traditional Chinese medicine Tiannianyin on the proliferation and transformation of lymphocytes in aging rats," Journal of Clinical Rehabilitative Tissue Engineering Research, vol. 11, no. 12, pp. 2368-2370, 2007.

[17] H.-B. Deng, D.-P. Cui, J.-M. Jiang, Y.-C. Feng, N.-S. Cai, and D.-D. Li, "Inhibiting effects of Achyranthes bidentata polysaccharide and Lycium barbarum polysaccharide on nonenzyme glycation in D-galactose induced mouse aging model," Biomedical and Environmental Sciences, vol. 16, no. 3, pp. 267-275, 2003.

[18] Z. K. Li and D. D. Li, "The immunomodulatory effect of Achyranthes bidentata polysaccharides," Yaoxue Xuebao, vol. 32, no. 12, pp. 881-887, 1997.

[19] S. D. Lee, The effect of achyranthis radix and apitoxin aquaacupuncture on cellular immune responses to LPS-induced arthritis in mice [Ph.D. thesis], Graduate School, Dongguk University, 1998. 
[20] C. S. Kim and Y. K. Park, "The therapeutic effect of achyranthis radix on the collagen-induced arthritis in mice," The Korea Journal of Herbology, vol. 25, no. 4, pp. 129-135, 2010.

[21] D. H. Roh, Effect of AR (achyranthis radix) on animal arthritic model [M.S. thesis], Graduate School, Dongguk University, Seoul, Republic of Korea, 2003.

[22] W. S. Do, Effects of aqua-acupuncture (Cortex Ulmi Pumilae, Ramulus Cinnamomum, Radix achyranthis, Apitoxin, Calculus Bovis, Fel Ursi, Moschus compound) in mice with lipopolysaccharide induced arthritis, Graduate School, Dongguk University, 1999.

[23] R. Fang, Q.-C. Meng, Y.-J. Deng, G. Song, and Y.-P. Bai, “Effects of Bu Shen Tong Luo decoction on matrix metalloproteinase1, matrix metalloproteinase-3, tissue inhibitor of matrix metalloprotease- 1 and interleukin-1beta content in the synovial fluid and serum of patients with knee osteoarthritis," Journal of Clinical Rehabilitative Tissue Engineering Research, vol. 12, no. 28, pp. 5581-5585, 2008.

[24] F. de Costa, A. C. A. Yendo, J. D. Fleck, G. Gosmann, and A. G. Fett-Neto, "Immunoadjuvant and anti-inflammatory plant saponins: characteristics and biotechnological approaches towards sustainable production," Mini-Reviews in Medicinal Chemistry, vol. 11, no. 10, pp. 857-880, 2011.

[25] M. Jia, Y. Nie, D.-P. Cao et al., "Potential antiosteoporotic agents from plants: a comprehensive review," Evidence-Based Complementary and Alternative Medicine, vol. 2012, Article ID 364604, 28 pages, 2012.

[26] C. H. Kim, "The study on treatment of climacteric disorder? (Osteoporosis)," Theses, vol. 32, no. 2, 1996.

[27] M. H. Oh, P. J. Houghton, W. K. Whang, and J. H. Cho, "Screening of Korean herbal medicines used to improve cognitive function for anti-cholinesterase activity," Phytomedicine, vol. 11, no. 6, pp. 544-548, 2004.

[28] H. Choi, S. H. Kim, D. Y. Lee, D. J. Ahn, W. H. Kang, and Y. S. Lyu, "The effects of Rhizoma Acori Graminei water extract in Alzheimer's disease model induced by pCT105," Journal of Oriental Neuropsychiatry, vol. 13, no. 2, pp. 173-194, 2002.

[29] H. Zhang, T. Han, C.-H. Yu, K. Rahman, L.-P. Qin, and C. Peng, "Ameliorating effects of essential oil from Acori graminei rhizoma on learning and memory in aged rats and mice," Journal of Pharmacy and Pharmacology, vol. 59, no. 2, pp. 301309, 2007.

[30] S. Bayati and R. Yazdanparast, "Antioxidant and free radical scavenging potential of yakuchinone $\mathrm{B}$ derivatives in reduction of lipofuscin formation using $\mathrm{H}_{2} \mathrm{O}_{2}$-treated neuroblastoma cells," Iranian Biomedical Journal, vol. 15, no. 4, pp. 134-142, 2011.

[31] G.-F. Shi, L.-J. An, B. Jiang, S. Guan, and Y.-M. Bao, "Alpinia protocatechuic acid protects against oxidative damage in vitro and reduces oxidative stress in vivo," Neuroscience Letters, vol. 403, no. 3, pp. 206-210, 2006.

[32] X. Zhang, G.-F. Shi, X.-Z. Liu, L.-J. An, and S. Guan, "Antiageing effects of protocatechuic acid from Alpinia on spleen and liver antioxidative system of senescent mice," Cell Biochemistry and Function, vol. 29, no. 4, pp. 342-347, 2011.

[33] P. Melgarejo, Á. Calín-Sánchez, Á. A. Carbonell-Barrachina et al., "Antioxidant activity, volatile composition and sensory profile of four new very-early apricots (Prunus armeniaca L.)," Journal of the Science of Food and Agriculture, vol. 94, no. 1, pp. 85-94, 2014.

[34] C.-Y. O. Chen and J. B. Blumberg, "In vitro activity of almond skin polyphenols for scavenging free radicals and inducing quinone reductase," Journal of Agricultural and Food Chemistry, vol. 56, no. 12, pp. 4427-4434, 2008.

[35] B. P. Halloran, T. J. Wronski, D. C. VonHerzen et al., "Dietary dried plum increases bone mass in adult and aged male mice," Journal of Nutrition, vol. 140, no. 10, pp. 1781-1787, 2010.

[36] H. Wang, S. Zhang, A. Guo, and J. Zhang, "Effects of almond on D-gal-induced aging rats," Wei Sheng Yan Jiu, vol. 33, no. 2, pp. 222-224, 2004.

[37] C.-Y. Che, P. E. Milbury, K. Lapsley, and J. B. Blumberg, "Flavonoids from almond skins are bioavailable and act synergistically with vitamins $\mathrm{C}$ and $\mathrm{E}$ to enhance hamster and human LDL resistance to oxidation," Journal of Nutrition, vol. 135, no. 6, pp. 1366-1373, 2005.

[38] B. Shukitt-Hale, W. Kalt, A. N. Carey, M. Vinqvist-Tymchuk, J. McDonald, and J. A. Joseph, "Plum juice, but not dried plum powder, is effective in mitigating cognitive deficits in aged rats," Nutrition, vol. 25, no. 5, pp. 567-573, 2009.

[39] J. Delgado, M. Del Pilar Terrón, M. Garrido et al., "Systemic inflammatory load in young and old ringdoves is modulated by consumption of a Jerte Valley cherry-based product," Journal of Medicinal Food, vol. 15, no. 8, pp. 707-712, 2012.

[40] A. Cilla, G. de Palma, M. J. Lagarda et al., "Impact of fruit beverage consumption on the antioxidant status in healthy women," Annals of Nutrition and Metabolism, vol. 54, no. 1, pp. 35-42, 2009.

[41] T. Traustadóttir, S. S. Davies, A. A. Stock et al., “Tart cherry juice decreases oxidative stress in healthy older men and women," Journal of Nutrition, vol. 139, no. 10, pp. 1896-1900, 2009.

[42] C. Reicks, J. Groathouse, M. Trauernicht et al., "Wild Plum: novel blue fluorescent compounds capable of luminosity restoration in sun-exposed skin," Skin Research and Technology, vol. 19, no. 1, pp. e465-e472, 2013.

[43] K.-H. Wang, R.-D. Lin, F.-L. Hsu et al., "Cosmetic applications of selected traditional Chinese herbal medicines," Journal of Ethnopharmacology, vol. 106, no. 3, pp. 353-359, 2006.

[44] S. Y. Lee, S. N. Kim, and J. K. Kim, "Effects of Asparagus cochinchinensis (Lour.) Merr. on the stimulation of osteoblast differentiation and inhibition of osteoclast generation," Journal of the Korean Society of Food Science and Nutrition, vol. 37, no. 1, pp. 16-19, 2008.

[45] D. Xiong, L.-X. Yu, X. Yan, C. Guo, and Y. Xiong, "Effects of root and stem extracts of Asparagus cochinchinensis on biochemical indicators related to aging in the brain and liver of mice," The American Journal of Chinese Medicine, vol. 39, no. 4, pp. 719726, 2011

[46] N. Shi, J. Su, Z.-B. Yang, G.-Y. Lü, and S.-H. Chen, "Antoxidantive effect of polysaccharides from Atractylodes macrocephala in D-galactose-induced aging mice," Chinese Journal of New Drugs, vol. 23, no. 5, pp. 577-584, 2014.

[47] S.-H. Kim and Y.-K. Park, "Effects of Atractylodis Rhizoma Alba extract on collagen-induced arthritis in mice," The Korea Journal of Herbology, vol. 27, no. 3, pp. 1-6, 2012.

[48] S.-J. Kang, A.-J. Kim, M.-S. Lee, Y.-H. Lee, and J.-K. Ji, “ The effect of enhancing eye-wrinkle applying traditional herb medicine cosmetics," Journal of the Korea Academia-Industrial Cooperation Society, vol. 12, no. 1, pp. 335-340, 2011.

[49] S.-J. Kang, A.-J. Kim, M.-S. Lee, and Y.-H. Lee, "Anti-wrinkle effect of oriental medicine cosmetics containing black ginseng," Journal of the Korea Academia-Industrial Cooperation Society, vol. 11, no. 9, pp. 3325-3329, 2010. 
[50] Y. S. Pathare and V. D. Wagh, "Herbal medicines and nutritional supplements used in the treatment of glaucoma: a review," Research Journal of Pharmaceutical, Biological and Chemical Sciences, vol. 3, no. 1, pp. 331-339, 2012.

[51] L. Li, X.-T. Qu, and Y. Lu, "Screening for phytoestrogens and their anti-skin aging effect in vitro," Journal of Shanghai Jiaotong University (Medical Science), vol. 31, no. 10, pp. 1361-1365, 2011.

[52] T. H. Park, D. H. Kim, C. H. Kim et al., "Peroxynitrite scavenging mode of alaternin isolated from Cassia tora," Journal of Pharmacy and Pharmacology, vol. 56, no. 10, pp. 1315-1321, 2004.

[53] C.-T. Horng, M.-L. Tsai, S.-T. Chien et al., "The activity of lowering intraocular pressure of cassiae seed extract in a DBA/2J mouse glaucoma model," Journal of Ocular Pharmacology and Therapeutics, vol. 29, no. 1, pp. 48-54, 2013.

[54] K. Muramoto, R.-D. Quan, T. Namba et al., "Ameliorative effects of Eriobotrya japonica seed extract on cellular aging in cultured rat fibroblasts," Journal of Natural Medicines, vol. 65, no. 2, pp. 254-261, 2011.

[55] D. S. Shin, Y. I. Kim, and H. Lee, "Effect of herbal-acupuncture with chaenomelis fructus solution at the Joksamni(ST36) of mice with Collagen-induced Aarthritis," Journal of Korean Acupuncture \& Moxibustion Medicine Society, vol. 24, no. 3, pp. 127-143, 2007.

[56] J. A. Lee, S. H. Noh, D. K. Ann, and H. Y. Choi, "Effects of the Eucommiae cortex and chanenomelis fructus on the aged ovariectomized rat of postmenopausal osteoporosis," The Korea Journal of Herbology, vol. 16, no. 1, pp. 201-206, 2001.

[57] F.-P. Chen, C.-M. Chang, S.-J. Hwang, Y.-C. Chen, and F.J. Chen, "Chinese herbal prescriptions for osteoarthritis in Taiwan: analysis of national health insurance dataset," BMC Complementary and Alternative Medicine, vol. 14, article 91, 2014.

[58] M. S. Kim, The scavenging effect of oriental medicines and oriental prescriptions on 1,1-diphenyl-2-picrylhydarzyl radical [M.S. thesis], Graduate School, Sunchon National University, 2004.

[59] S. C. Lee, H. E. Yang, B. K. Jo, H. P. Kim, and M. Y. Heo, "Protective effects of ellagic acid and inner shell of chestnut on hydrogen peroxide-induced oxidative DNA damage," in Proceedings of the International Symposium on Dietary and Medicinal Antimutgens and Anticarcinogens, vol. 10, p. 110, 2001.

[60] J. Y. Kim, Anti-aging activities of Castanea crenata leaf extract/fractions and application on cosmetics [M.S. thesis], Graduate School, Seoul National University of Technology, 2009.

[61] M. J. Jang, D. H. Jun, S. H. Kim, S. I. Han, and J. T. Lee, "Antiwrinkle effect of chestnut leaf," Journal of Life Sciences, vol. 23, no. 6, pp. 751-756, 2013.

[62] M.-J. Jang, S.-J. Cheon, H.-Y. Kim et al., "The anti-wrinkle and whitening effect of extracts of Castanea crenata inner shell," Journal of Life Science, vol. 21, no. 5, pp. 734-738, 2011.

[63] A. Y. Park, Effects of extracts from chestnut inner shell on skin [M.S. thesis], Graduate School, Catholic University of Daegu, 2012.

[64] W. K. Tseng, Y. S. Chen, and C. C. Kwan, "Study of chrysanthemum morifolium flowers extract on the efficacy of antioxidation, inhibiting the formation of melanin and antimutagenicity," Taiwanese Journal of Agricultural Chemistry and Food Science, vol. 47, no. 1, pp. 47-54, 2009.

[65] E. S. Choung, Screening and evaluation of cosmeceuticals from medicinal plants [Ph.D. thesis], Graduate School, SungKyunKwan University, 2007.
[66] P.-H. Zhang, H.-Q. Tang, M.-Z. Zheng, Y.-Y. Chen, and Y.L. Shen, "Effect of total flavonoids from Chrysanthemun morifolium on learning and memory in aging mice," Zhongguo Ying Yong Sheng Li Xue Za Zhi, vol. 27, no. 3, pp. 368-371, 2011.

[67] B.-C. Lee, S. Y. Lee, H. J. Lee et al., "Anti-oxidative and photo-protective effects of coumarins isolated from Fraxinus chinensis," Archives of Pharmacal Research, vol. 30, no. 10, pp. 1293-1301, 2007.

[68] P. K. Mukherjee, N. Maity, N. K. Nema, and B. K. Sarkar, "Bioactive compounds from natural resources against skin aging," Phytomedicine, vol. 19, no. 1, pp. 64-73, 2011.

[69] M. K. Ghadiri and A. Gorji, "Natural remedies for impotence in medieval Persia," International Journal of Impotence Research, vol. 16, no. 1, pp. 80-83, 2004.

[70] K. P. Lee and J. Y. Moon, "Pinus densiflora gnarl extract for pharmacopuncture inhibits inflammatory responses through heme oxygenase-1 induction in lipopolysaccharide-stimulated RAW264.7 macrophages," Korean Journal of Acupuncture, vol. 29, no. 1, pp. 37-46, 2012.

[71] Y. J. Mun, N. Y. Lim, S. W. Lee, D. G. Kang, S. K. Baik, and W. H. Woo, "Antioxidative effects of the fermented extract of Pinus densiflora," The Korean Journal of Oriental Medical Prescription, vol. 10, no. 2, pp. 243-249, 2002.

[72] S. K. Park, J. C. Lee, S. M. Ahn et al., "Anti-aging effect on skin with the needles of red pine, Pinus densiflora," The Korea Journal of Herbology, vol. 20, no. 4, pp. 1-10, 2005.

[73] C. S. Kwak, S. C. Moon, and M. S. Lee, "Antioxidant, antimutagenic, and antitumor effects of pine needles (Pinus densiflora)," Nutrition and Cancer, vol. 56, no. 2, pp. 162-171, 2006.

[74] J. H. Choi, D. I. Kim, S. H. Park, D. W. Kim, J. S. Lee, and H. S. Kim, "Investigation of anti-aging effect and determination of chemical structures of pine needle extract (PNE) through the animal experiments I. Effects of PNE on membrane fluidity and oxidative stress in liver of SD," Korean Journal of Life Science, vol. 9, no. 4, pp. 473-480, 1999.

[75] J. H. Choi, D. I. Kim, S. H. Park et al., "Effects of butanol fraction of pine needle (Pinus densiflora) on oxygen radicals and their scavenger enzymes in liver of SD rats," The Korean Journal of Nutrition, vol. 35, no. 3, pp. 291-295, 2002.

[76] J. H. Choi, S. H. Park, D. I. Kim, C. M. Kim, J. H. Lee, and H. S. Kim, "Effects of butanol fraction of pine needle (pinus densiflora) on serum lipid metabolism and oxidative stress in rats," The Korean Journal of Nutrition, vol. 35, no. 3, pp. 296302, 2002.

[77] E. J. Kim, S. Y. Ahn, G. W. Nam et al., "The anti-aging effects of the cosmetic products containing the needles of red pine on human skin," The Korea Journal of Herbology, vol. 21, no. 1, pp. 25-31, 2006.

[78] C. J. Yu, M. F. Zheng, C. X. Kuang, W. D. Huang, and Q. Yang, "Oren-gedoku-to and its constituents with therapeutic potential in Alzheimer's Disease inhibit indoleamine 2,3-dioxygenase activity in vitro," Journal of Alzheimer's Disease, vol. 22, no. 1, pp. 257-266, 2010.

[79] H.-J. Hong, P. O.-Y. Chen, T.-C. Shih et al., "Computational pharmaceutical analysis of anti-Alzheimer's Chinese medicine Coptidis Rhizoma alkaloids," Molecular Medicine Reports, vol. 5, no. 1, pp. 142-147, 2012.

[80] C. T. Tang, L. K. Belani, S. Das, and M. Z. Jaafar, "Treatment of dementia with herbs: a short review," Clinica Terapeutica, vol. 164, no. 1, pp. 43-46, 2013.

[81] N. Yamabe, K. S. Kang, C. H. Park, T. Tanaka, and T. Yokozawa, "7-O-galloyl-D-sedoheptulose is a novel therapeutic agent 
against oxidative stress and advanced glycation endproducts in the diabetic kidney," Biological and Pharmaceutical Bulletin, vol. 32, no. 4, pp. 657-664, 2009.

[82] H. Q. Lin, M. T. Ho, L. S. Lau, K. K. Wong, P. C. Shaw, and D. C. C. Wan, "Anti-acetylcholinesterase activities of traditional Chinese medicine for treating Alzheimer's disease," ChemicoBiological Interactions, vol. 175, no. 1-3, pp. 352-354, 2008.

[83] Y.-L. Wang, Q. Ou, X.-D. Wei et al., "Effect of fructus corni polysaccharides on expression of cyclinD1 and CDK4 in aging human diploid fibroblasts," Chinese Journal of Gerontology, vol. 28, no. 8, pp. 739-741, 2008.

[84] T. Li-li and Y. Lei, "Effect of fructus corni polysaccharides on the activity of $\beta$-galactosidase and the expression of p16," Chinese Journal of Gerontology, vol. 27, no. 4, pp. 325-327, 2007.

[85] J. A. Seo, Evaluation of antioxidant activities of dried and aged Corni Fructus [M.S. thesis], Graduate School, Korea University, 2013.

[86] M. S. Kim, D. W. Kim, and D. Y. Rhyu, "Screening of natural resources with inhibitory activity on free radicals and advanced glycation end products (AGEs) formation," Korean Journal of Pharmacognosy, vol. 37, no. 4, pp. 307-313, 2006.

[87] B. H. Jeong, Study on the pharmacological effects of corni fructus extracts by processing method [M.S. thesis], Graduate School, Sunchon National University, 2006.

[88] S. S. Choi, D. S. Yim, and S. Y. Lee, "Radical scavenging activities and protective effects against oxidative damage to DNA of extracts from medicinal plants with known osteoprotective effects," Korean Journal of Pharmacognosy, vol. 40, no. 2, pp. 143-149, 2009.

[89] H. H. Yu, S. J. Seo, J. M. Hur et al., "Protective effect of ursolic acid from Corni fructus on the hydrogen peroxide-induced damage of HEI-OC1 auditory cells," Korean Journal of Oriental Physiology and Pathology, vol. 20, no. 6, pp. 1524-1529, 2006.

[90] W. B. Lee, H. S. Jung, J. Kwon, C. H. Oh, and K. G. Lee, "Immunoregulatory action of Cornus officinalis sieb. et Zucc," Korean Journal of Oriental Physiology \& Pathology, vol. 16, no. 2, pp. 267-271, 2002.

[91] J. H. Zhou, C. S. Li, and D. D. Li, "Effect of cornus on NK activity, IL-2 activity and IL-2 mRNA expression in aging mice," Chinese Pharmaceutical Journal, vol. 35, no. 9, pp. 618-638, 2000.

[92] H. Xu, J. Shen, H. Liu, Y. Shi, H. Li, and M. Wei, "Morroniside and loganin extracted from Cornus officinalis have protective effects on rat mesangial cell proliferation exposed to advanced glycation end products by preventing oxidative stress," Canadian Journal of Physiology and Pharmacology, vol. 84, no. 12, pp. 1267-1273, 2006.

[93] K. S. Kim, G. M. Kim, H. Ji, S. W. Park, J. S. Yang, and C. J. Yang, "Effects of dietary Alisma canaliculatum (Alismatis rhizoma), Viscum album (Mistletoe) and Cornus officinalis (Corni fructus) probiotics as feed additives on growth performance and immunity in growing pigs," Korean Journal of Veterinary Service, vol. 33, no. 4, pp. 375-385, 2010.

[94] J.-M. Gao, R. Li, L. Zhang et al., "Cuscuta chinensis seeds water extraction protecting murine osteoblastic MC3T3-E1 cells against tertiary butyl hydroperoxide induced injury," Journal of Ethnopharmacology, vol. 148, no. 2, pp. 587-595, 2013.

[95] T.-C. Hsieh and J. M. Wu, "Ethanolic extracts of herbal supplement Equiguard suppress growth and control gene expression in CWR22Rv1 cells representing the transition of prostate cancer from androgen dependence to hormone refractory status," International Journal of Oncology, vol. 32, no. 1, pp. 209-219, 2008.
[96] X. M. Wang, H. Fu, and G. X. Liu, "Effect of wuzi yanzong pill and its disassembled prescription on mitochondrial DNA deletion, respiratory chain complexes and ATP synthesis in aged rats," Chinese Journal of Integrated Traditional and Western Medicine, vol. 21, no. 6, pp. 437-440, 2001.

[97] S.-L. Sun, L. Guo, Y.-C. Ren et al., "Anti-apoptosis effect of polysaccharide isolated from the seeds of Cuscuta chinensis Lam on cardiomyocytes in aging rats," Molecular Biology Reports, vol. 41, no. 9, pp. 6117-6124, 2014.

[98] D. N. Qin, B. R. She, Y. C. She, and J. H. Wang, "Effects of flavonoids from semen cuscutae on the reproductive system in male rats," Asian Journal of Andrology, vol. 2, no. 2, pp. 99-102, 2000.

[99] S. H. Kim and J. W. Choi, "Protective effects of water extract from cuscutae semen on ketoconazole-induced oxidative stress in testicular damage male rats," Korean Journal of Oriental Physiology \& Pathology, vol. 25, no. 3, pp. 417-424, 2011.

[100] C. C. W. Chan, W. N. T. Lau, S.-P. Chiu, L.-C. Chen, W.K. I. Choi, and G. W. K. Tang, "A pilot study on the effects of a Chinese herbal preparation on menopausal symptoms," Gynecological Endocrinology, vol. 22, no. 2, pp. 70-73, 2006.

[101] M. S. Lee, K.-W. Park, J.-S. Park, H.-J. Kim, and S.-R. Moon, "Effects of nutritional supplement with herbal extract on bone mineral density and height in prepubescent children-a preliminary study," Phytotherapy Research, vol. 19, no. 9, pp. 810-811, 2005.

[102] J. Wang and F.-L. Li, "Randomized-conrolled observation of naolibao in improvement of memory impairment in aged people wih yin deficiency of liver and kidney," Chinese Journal of Clinical Rehabilitation, vol. 10, no. 3, pp. 163-166, 2006.

[103] C. S. Li, H. B. Deng, D. D. Li, and Z. H. Li, "Advances and challenges in screening traditional Chinese anti-aging materia medica," Chinese Journal of Integrative Medicine, vol. 19, no. 4, pp. 243-252, 2013.

[104] D. B. Rao, C. R. Kiran, Y. Madhavi, P. K. Rao, and T. R. Rao, "Evaluation of antioxidant potential of Clitoria ternata L. and Eclipta prostrata L.," Indian Journal of Biochemistry and Biophysics, vol. 46, no. 3, pp. 247-252, 2009.

[105] R. C. Rawal, P. Gandhi, T. B. Singh, and K. H. H. V. S. S. N. Murthy, "Clinical evaluation of hairbac tablet and oil in the management of diffuse hair loss: an open clinical study," International Journal of Research in Ayurveda and Pharmacy, vol. 4, no. 4, pp. 564-569, 2013.

[106] G.-J. Fan, X.-Y. Tang, and S.-L. Li, "Effects of Jiangtang Bushen Recipe on serum C-reactive protein, tumor necrosis factoralpha and interleukin- 6 in patients with type 2 diabetes mellitus," Chinese Journal of Integrated Traditional and Western Medicine, vol. 26, no. 4, pp. 329-331, 2006.

[107] X.-H. Duan, C.-Q. Xu, J.-H. Huang, W.-J. Zhou, and B. Sun, "Icariin delays homocysteine-induced endothelial cellular senescence involving activation of the PI3K/AKT-eNOS signaling pathway," Pharmaceutical Biology, vol. 51, no. 4, pp. 433-440, 2013.

[108] N. Zeng, X. Meng, Y. Zhang et al., "Antioxidative effect of constituents of Herba Epimedii (ESPS)," Zhongguo Zhong Yao Za Zhi, vol. 22, no. 1, pp. 46-63, 1997.

[109] X. Meng, N. Zeng, Y. Zhang, X. Lai, C. Ren, and L. Cheng, "Effect of active constituents of Herba Epimedii on hypothalamic monoamine neurotransmitters and other brain functions in aging rats," Zhongguo Zhong Yao Za Zhi, vol. 21, no. 11, pp. 683-685, 1996. 
[110] X.-Y. Liu, Q. Wang, S.-J. Xia, J.-H. Huang, Z.-Y. Shen, and $\mathrm{H}$. Xu, "Characteristics of lymphocyte nuclear factor- $\kappa \mathrm{B}$ signal transduction kinase expression in aging process and regulatory effect of Epimedium flavonoids," Chinese Journal of Integrative Medicine, vol. 17, no. 9, pp. 704-709, 2011.

[111] L. Xue, Y. Wang, Y. Jiang et al., "Comparative effects of ErXian decoction, Epimedium herbs, and icariin with estrogen on bone and reproductive tissue in ovariectomized rats," EvidenceBased Complementary and Alternative Medicine, vol. 2012, no. 11, Article ID 241416, 2012.

[112] M. N. Makarova, O. N. Pozharitskaya, A. N. Shikov, S. V. Tesakova, V. G. Makarov, and V. P. Tikhonov, "Effect of lipidbased suspension of Epimedium koreanum Nakai extract on sexual behavior in rats," Journal of Ethnopharmacology, vol. 114, no. 3, pp. 412-416, 2007.

[113] J. Cai, T. Zheng, L. Zhang, Y. Tian, M.-H. Yang, and J. Du, "Effects of Herba Epimedii and Fructus Ligustri lucidi on the transcription factors in hypothalamus of aged rats," Chinese Journal of Integrative Medicine, vol. 17, no. 10, pp. 758-763, 2011.

[114] Q. Li, J. Liao, and T. Wu, "Epimedium sagittatum Maxim preventing hormone-induced osteoporosis in rats," Chinese Pharmaceutical Journal, vol. 31, no. 8, pp. 467-469, 1996.

[115] H. S. Kwon, Estrogenic effects of Epimedii herba extract, icariin, and icaritin in female rats [M.S. thesis], Graduate School, Korea University, 2008.

[116] B. Wu, Y. Chen, J. Huang et al., "Icariin improves cognitive deficits and activates quiescent neural stem cells in aging rats," Journal of Ethnopharmacology, vol. 142, no. 3, pp. 746-753, 2012.

[117] H. B. Lim and D. W. Lee, "Long-term supplementation of Epimedium koreanum Nakai in rats and its effects on in vivo antioxidant status with age," Food Science and Biotechnology, vol. 16, no. 3, pp. 404-408, 2007.

[118] B.-L. Xu, T. Wu, L. Cui, and Y.-Y. Liu, "The effects of epimedium pubescens flavonoids combined with diethylstilbestrol on ovariectomy induced osteopenia in rats," Chinese Pharmacological Bulletin, vol. 20, no. 2, pp. 218-222, 2004.

[119] H. J. Kim, Epimedium koreanum extract and its role in oxidative stress [M.S. thesis], Graduate School, Silla University, Busan, Republic of Korea, 2004.

[120] H. S. Lee and H. B. Lim, "Age-related changes in xenobiotic metabolizing systems of the liver by dietary supplementation of Epimedium koreanum Nakai water extracts in rats," Journal of Agricultural Science, Chungbuk National University, vol. 27, no. 4, pp. 209-214, 2011.

[121] Y. G. Lee, H. O. Sohn, D. W. Lee, and H. B. Lim, “The Effect of water-extract of Epimedium koreanum Nakai on age-related changes of the xenobiotic metabolizing enzyme system in the liver of rats," Korean Journal of Medicinal Crop Science, vol. 10, no. 1, pp. 29-36, 2002.

[122] H. J. Liao, X. M. Chen, and W. G. Li, "Effect of Epimedium sagittatum on quality of life and cellular immunity in patients of hemodialysis maintenance," Chinese Journal of Integrated Traditional and Western Medicine, vol. 15, no. 4, pp. 202-204, 1995.

[123] F.-F. Yan, Y. Liu, Y.-F. Liu, and Y.-X. Zhao, "Herba Epimedii water extract elevates estrogen level and improves lipid metabolism in postmenopausal women," Phytotherapy Research, vol. 22, no. 9, pp. 1224-1228, 2008.

[124] P. G. Xiao, S. T. Xing, and L. W. Wang, "Immunological aspects of Chinese medicinal plants as antiageing drugs," Journal of Ethnopharmacology, vol. 38, no. 2-3, pp. 167-175, 1993.
[125] K. Chen and C. Li, "Recent advances in studies on traditional Chinese anti-aging materia medica," Journal of Traditional Chinese Medicine, vol. 13, no. 3, pp. 223-226, 1993.

[126] M. L. Steele, J. Truong, S. Govindaraghavan, L. Ooi, N. J. Sucher, and G. Münch, "Cytoprotective properties of traditional Chinese medicinal herbal extracts in hydrogen peroxide challenged human U373 astroglia cells," Neurochemistry International, vol. 62, no. 5, pp. 522-529, 2013.

[127] J. N. Ho, H. Y. Cho, E. J. Lim, and H. K. Kim, "Effects of aucubin isolated from Eucommia ulmoides on UVB-induced oxidative stress in human keratinocytes HaCAT," Food Science and Biotechnology, vol. 18, no. 2, pp. 475-480, 2009.

[128] D. Załuski and H. D. Smolarz, "Plant inhibitors of metalloproteinases and the possibility of their aplication in the prevention of photoaging," Annales Universitatis Mariae Curie-Sklodowska, Sectio DDD: Pharmacia, vol. 22, no. 2, pp. 89-96, 2009.

[129] J. N. Ho, Protective effects of Eucommia ulmoides against UVB-induced skin damage in human fibroblasts and hairless mouse [Ph.D. thesis], Graduate School, Korea University, Seoul, Republic of Korea, 2005.

[130] J. Y. Kim, Effects of Eucommia ulmoides folium on antioxidation, gene expression and cytokines of 3T3-L1 cell line [Ph.D. thesis], Graduate School, Sangji University, 2007.

[131] Y. Kwon, Peroxynitrite scavenging mechanism of Eucommiae cortex [M.S. thesis], Graduate School, Dongguk University, 2003.

[132] W. Zhang, T. Fujikawa, K. Mizuno et al., "Eucommia leaf extract (ELE) prevents OVX-induced osteoporosis and obesity in rats," The American Journal of Chinese Medicine, vol. 40, no. 4, pp. 735-752, 2012.

[133] Y. Li, K. Metori, K. Koike, Q.-M. Che, and S. Takahashi, "Improvement in the turnover rate of the stratum corneum in false aged model rats by the administration of geniposidic acid in Eucommia ulmoides OLIVER leaf," Biological and Pharmaceutical Bulletin, vol. 22, no. 6, pp. 582-585, 1999.

[134] K. Metori, S.-Y. Tanimoto, and S. Takahashi, "Promotive effect of Eucommia leaf extract on collagen synthesis in rats," Natural Medicines, vol. 52, no. 6, pp. 465-469, 1998.

[135] J. N. Ho, Y. H. Lee, J. S. Park et al., "Protective effects of aucubin isolated from Eucommia ulmoides against UVBinduced oxidative stress in human skin fibroblasts," Biological and Pharmaceutical Bulletin, vol. 28, no. 7, pp. 1244-1248, 2005.

[136] K. Li, M. Liu, and X. Wei, "Study of xixin, duzhong and mixture to the antioxidant system of D-galactose-induced senile mice," Zhong Yao Cai, vol. 23, no. 3, pp. 161-163, 2000.

[137] Y. Li, S. Kamo, K. Metori, K. Koike, Q.-M. Che, and S. Takahashi, "The promoting effect of eucommiol from Eucommiae cortex on collagen synthesis," Biological and Pharmaceutical Bulletin, vol. 23, no. 1, pp. 54-59, 2000.

[138] Y. Li, T. Sato, K. Metori, K. Koike, Q.-M. Che, and S. Takahashi, "The promoting effects of geniposidic acid and aucubin in Eucommia ulmoides oliver leaves on collagen synthesis," Biological and Pharmaceutical Bulletin, vol. 21, no. 12, pp. 1306-1310, 1998.

[139] H. S. Oh, H. C. Kim, S. I. Lee, and D. K. Ahn, "Effects of Eucommiae cortex and folium on the ovariectomized rat as the model of postmenopaual osteoporosis," The Korea Journal of Herbology, vol. 10, no. 1, pp. 59-68, 1995.

[140] I. S. Lee, Effects of Eucommiae cortex administration on shortterm memory, cell proliferation, and cell death in the hippocampus of aged rats [Ph.D. thesis], Graduate School, Kyungwon University, 2010. 
[141] X. He, J. Wang, M. Li et al., "Eucommia ulmoides oliv.: ethnopharmacology, phytochemistry and pharmacology of an important traditional Chinese medicine," Journal of Ethnopharmacology, vol. 151, no. 1, pp. 78-92, 2014.

[142] Z. Kang, W.-H. Wu, J.-J. Wang, and D.-S. Ouyang, "Research advances in pharmacology of aucubin and aucubigenin," Zhongguo Zhongyao Zazhi, vol. 32, no. 24, pp. 2585-2587, 2007.

[143] C. Y. Wu, R. Chen, X. S. Wang, B. Shen, W. Yue, and Q. Wu, "Antioxidant and anti-fatigue activities of phenolic extract from the seed coat of Euryale ferox Salisb. and identification of three phenolic compounds by LC-ESI-MS/MS," Molecules, vol. 18, no. 9, pp. 11003-11021, 2013.

[144] N. Izzati Osman, A. Awal, N. Jaafar Sidik, and S. Abdullah, "In vitro regeneration and antioxidant propertiesof Lycium barbarum L. (goji)," Jurnal Teknologi (Sciences and Engineering), vol. 62, no. 2, pp. 35-38, 2013.

[145] Y. S. Ho, M. S. Yu, C. S. W. Lai, K. F. So, W. H. Yuen, and R. C. C. Chang, "Characterizing the neuroprotective effects of alkaline extract of Lycium barbarum on beta-amyloid peptide neurotoxicity," Brain Research, vol. 1158, no. 1, pp. 123-134, 2007.

[146] D. E. Breithaupt, P. Weller, M. Wolters, and A. Hahn, "Comparison of plasma responses human subjects after the ingestion of $3 R, 3 R^{\prime}$-zeaxanthin dipalmitate from wolfberry (Lycium barbarum) and non-esterified $3 \mathrm{R}, 3 \mathrm{R}^{\prime}$-zeaxanthin using chiral high-performance liquid chromatography," British Journal of Nutrition, vol. 91, no. 5, pp. 707-713, 2004.

[147] L. Liu, X.-N. Wang, Z. Liu et al., "Effect of lycium bararum polysaccharides on angiotensin II-induced senescence of human umbilical vein endothelial cells and expressions of P53 and P16," Nan Fang Yi Ke Da Xue Xue Bao, vol. 31, no. 7, pp. 1212-1215, 2011.

[148] S.-J. Lee, Y.-Y. Kwon, S.-W. Cho, H.-S. Kwon, and W.-C. Shin, "Effects of ehwa makgeolli containing oriental herbs on skin whitening and wrinkles," Journal of the Korean Society of Food Science and Nutrition, vol. 42, no. 4, pp. 550-555, 2013.

[149] X. Xu, L. Hang, B. Huang, Y. Wei, S. Zheng, and W. Li, "Efficacy of ethanol extract of Fructus lycii and its constituents lutein/zeaxanthin in protecting retinal pigment epithelium cells against oxidative stress: in vivo and in vitro models of agerelated macular degeneration," Journal of Ophthalmology, vol. 2013, Article ID 862806, 10 pages, 2013.

[150] J.-H. Zou, H.-Y. Liang, L. Liu, L.-F. Min, Y.-R. Tang, and B.-Y. Wu, "Influence of medlar on the lifespan of human fibroblasts and gene expression of c-fos," Chinese Journal of Clinical Rehabilitation, vol. 9, no. 7, pp. 110-111, 2005.

[151] G. Xia, N. Xin, W. Liu, H. Yao, Y. Hou, and J. Qi, "Inhibitory effect of Lycium barbarum polysaccharides on cell apoptosis and senescence is potentially mediated by the p53 signaling pathway," Molecular Medicine Reports, vol. 9, no. 4, pp. 12371241, 2014.

[152] Y.-S. Ho, M.-S. Yu, X.-F. Yang, K.-F. So, W.-H. Yuen, and R. C.-C. Chang, "Neuroprotective effects of polysaccharides from wolfberry, the fruits of Lycium barbarum, against homocysteineinduced toxicity in rat cortical neurons," Journal of Alzheimer's Disease, vol. 19, no. 3, pp. 813-827, 2010.

[153] X.-J. Du, W.-H. Dong, H.-S. Bi, and X.-F. Xie, "The antiaging effect of Lycium barbarum polysaccharide on human retinal pigment epithelial cell," Chinese Journal of Experimental Ophthalmology, vol. 31, no. 8, pp. 739-743, 2013.

[154] H. E. Yu, L. M. M. Dela Paz, Y. J. Bae et al., "Screening and extraction condition of antiaging bioactive substances from medicinal plants," Journal of the Korean Society of Food Science and Nutrition, vol. 34, no. 8, pp. 1136-1142, 2005.

[155] Y. Shin, Flavor improvement effect of Lycii fructus by steam blanching, microwave blanching and deodorizing [M.S. thesis], Graduate School, Chungnam National University, 2001.

[156] J. E. Yoon, Experimental study about the effect on collagen synthesis by several herbal medicines [M.S. thesis], Graduate School, Wonkwang University, 2010.

[157] D.-C. Shin, G.-C. Kim, S.-Y. Song, H.-J. Kim, J.-C. Yang, and B.-A. Kim, "Antioxidant and antiaging activities of complex supercritical fluid extracts from dendropanax morbifera, Corni fructus and Lycii fructus," The Korea Journal of Herbology, vol. 28, no. 6, pp. 95-100, 2013.

[158] D.-C. Shin, G.-C. Kim, S.-Y. Song et al., "Antiaging activity of mixed extracts from Korean medicinal herbs on HS68 skin fibroblast," The Korea Journal of Herbology, vol. 29, no. 2, pp. 39-45, 2014.

[159] W.-H. Dong, X.-J. Du, D.-D. Guo, R. Dou, X.-F. Xie, and H.$\mathrm{S}$. Bi, "Protective effects of Lycium barbarum polysaccharide on damaged hRPE cells induced by blue light irradiation," International Eye Science, vol. 13, no. 12, pp. 2381-2384, 2013.

[160] R. Yi, X.-M. Liu, and Q. Dong, "A study of Lycium barbarum polysaccharides (LBP) extraction technology and its anti-aging effect," African Journal of Traditional, Complementary, and Alternative Medicines, vol. 10, no. 4, pp. 171-174, 2013.

[161] M. He, H. Pan, R. C.-C. Chang, K.-F. So, N. C. Brecha, and $\mathrm{M}$. Pu, "Activation of the Nrf2/HO-1 antioxidant pathway contributes to the protective effects of Lycium barbarum polysaccharides in the rodent retina after ischemia-reperfusioninduced damage," PLoS ONE, vol. 9, no. 1, Article ID e84800, 2014.

[162] W.-Z. Jiang and H.-Q. Zhang, "Anti-aging effect of polypeptides from Fructus lycii on D-gal induced aging model mice and the possible mechanism," Journal of International Pharmaceutical Research, vol. 37, no. 1, pp. 47-50, 2010.

[163] H. Amagase, "Antioxidants in Goji Berry juice (Lycium barbarum) and effects of processing steps," in Processing and Impact on Antioxidants in Beverages, pp. 155-163, 2014.

[164] A. Cilla, G. De Palma, M. J. Lagarda et al., "Impact of fruit beverage consumption on the antioxidant status in healthy women," Annals of Nutrition and Metabolism, vol. 54, no. 1, pp. 35-42, 2009.

[165] M.-S. Yu, C. S.-W. Lai, Y.-S. Ho et al., "Characterization of the effects of anti-aging medicine Fructus lycii on $\beta$-amyloid peptide neurotoxicity," International Journal of Molecular Medicine, vol. 20, no. 2, pp. 261-268, 2007.

[166] M. S. Yu, Y. S. Ho, K. F. So, W. H. Yuen, and R. C. C. Chang, "Cytoprotective effects of Lycium barbarum against reducing stress on endoplasmic reticulum," International Journal of Molecular Medicine, vol. 17, no. 6, pp. 1157-1161, 2006.

[167] J. Li, Q. Ou, T. Zhang, D.-F. Bai, and J. Yang, "Effect of Lycium barbarum polysaccharides on expression of DNA repairase 8oxoguanine gene in liver of aging model rats induced by $\mathrm{D}$ galactose," Chinese Journal of Clinical Rehabilitation, vol. 10, no. 7, pp. 102-104, 2006.

[168] X.-S. Mi, K. Chiu, G. Van et al., "Effect of Lycium barbarum polysaccharides on the expression of endothelin-1 and its receptors in an ocular hypertension model of rat glaucoma," Neural Regeneration Research, vol. 7, no. 9, pp. 645-651, 2012.

[169] X. M. Li, Y. L. Ma, and X. J. Liu, "Effect of the Lycium barbarum polysaccharides on age-related oxidative stress in aged mice," Journal of Ethnopharmacology, vol. 111, no. 3, pp. 504-511, 2007. 
[170] J. J. Ji, L. S. Han, and J. Xu, "Effects of Fructus lycii on learning and memory of D-galactose induced aging mice," Chinese Journal of Public Health, vol. 23, no. 3, pp. 359-368, 2007.

[171] H. G. Kim and M. S. Oh, "Memory-enhancing effect of Mori Fructus via induction of nerve growth factor," British Journal of Nutrition, vol. 110, no. 1, pp. 86-94, 2013.

[172] L. Xiang and L. Jie, "Experimental research on the skin antiaging function of vitamin $\mathrm{E}$ and Lycium barbarum polysaccharides in rats," Modern Journal of Integrated Chinese Traditional and Western Medicine, vol. 18, no. 13, pp. 1465-1466, 2009.

[173] M. Ahn, J. S. Park, S. Chae et al., "Hepatoprotective effects of Lycium chinense miller fruit and its constituent betaine in $\mathrm{CCl}_{4}{ }^{-}$ induced hepatic damage in rats," Acta Histochemica, vol. 116, no. 6, pp. 1104-1112, 2014.

[174] J. Liang, C.-W. Zhang, J.-C. Li, S. J. Luo, and X. G. Hao, "Influence of Lycium barbarum polysaccharides on activity of superoxide dismutase in rat skins," Journal of Clinical Rehabilitative Tissue Engineering Research, vol. 11, no. 36, pp. 7207-7210, 2007.

[175] D. Yang, S.-Y. Li, C.-M. Yeung et al., "Lycium barbarum extracts protect the brain from blood-brain barrier disruption and cerebral edema in experimental stroke," PLoS ONE, vol. 7, no. 3, Article ID e33596, 2012.

[176] W. Chen, X. Cheng, J. Chen et al., "Lycium barbarum polysaccharides prevent memory and neurogenesis impairments in scopolamine-treated rats," PLoS ONE, vol. 9, no. 2, Article ID e88076, 2014.

[177] M. Cai, B. Y. Shin, D. H. Kim et al., "Neuroprotective effects of a traditional herbal prescription on transient cerebral global ischemia in gerbils," Journal of Ethnopharmacology, vol. 138, no. 3, pp. 723-730, 2011.

[178] M.-S. Yu, S. K.-Y. Leung, S.-W. Lai et al., "Neuroprotective effects of anti-aging oriental medicine Lycium barbarum against $\beta$-amyloid peptide neurotoxicity," Experimental Gerontology, vol. 40, no. 8-9, pp. 716-727, 2005.

[179] H.-C. Chan, R. C.-C. Chang, A. Koon-Ching Ip et al., "Neuroprotective effects of Lycium barbarum Lynn on protecting retinal ganglion cells in an ocular hypertension model of glaucoma," Experimental Neurology, vol. 203, no. 1, pp. 269-273, 2007.

[180] Y. S. Ho, M. S. Yu, S. Y. Yik, K. F. So, W. H. Yuen, and R. C. C. Chang, "Polysaccharides from wolfberry antagonizes glutamate excitotoxicity in rat cortical neurons," Cellular and Molecular Neurobiology, vol. 29, no. 8, pp. 1233-1244, 2009.

[181] B.-L. Huang, S.-H. Ding, L. Hang, S.-Z. Zheng, W. Li, and $\mathrm{X} .-\mathrm{R}$. $\mathrm{Xu}$, "Prevention and treatment of age-related macular degeneration by extract of Fructus lycii and its constituents lutein/zeaxanthin: an in vive and in vitro experimental research," Zhongguo Zhong Xi Yi Jie He Za Zhi, vol. 33, no. 4, pp. 531-537, 2013.

[182] T. Tang and B. He, "Treatment of d-galactose induced mouse aging with Lycium barbarum polysaccharides and its mechanism study," African Journal of Traditional, Complementary and Alternative, vol. 10, no. 4, pp. 12-17, 2013.

[183] L.-G. Yuan, H.-B. Deng, L.-H. Chen, D.-D. Li, and Q.-Y. He, "Reversal of apoptotic resistance by Lycium barbarum glycopeptide 3 in aged T cells," Biomedical and Environmental Sciences, vol. 21, no. 3, pp. 212-217, 2008.

[184] M. H. Kim, "Effect of Lycii fructus extracts on serum lipids and bone collagen contents in ovariectomized rats," Korean Journal of Oriental Physiology and Pathology, vol. 21, no. 1, pp. 111-116, 2007.
[185] C. Y. Cheng, W. Y. Chung, Y. T. Szeto, and I. F. F. Benzie, “Fasting plasma zeaxanthin response to Fructus barbarum L. (wolfberry; Kei Tze) in a food-based human supplementation trial," British Journal of Nutrition, vol. 93, no. 1, pp. 123-130, 2005.

[186] P. Bucheli, K. Vidal, L. Shen et al., "Goji berry effects on macular characteristics and plasma antioxidant levels," Optometry and Vision Science, vol. 88, no. 2, pp. 257-262, 2011.

[187] D. J. Yang, "Tinnitus treated with combined traditional Chinese medicine and Western medicine," Chinese Journal of Modern Developments in Traditional Medicine, vol. 9, no. 5, pp. 270-259, 1989.

[188] R. M. G. Pons and E. G. Ventura, "Goji berries (Lycium barbarum L.): pharmacological aspects and effectiveness," Revista de Fitoterapia, vol. 10, no. 1, pp. 23-33, 2010.

[189] O. Potterat and M. Hamburger, "Goji juice: a novel miraculous cure for longevity and well-being? A review of composition, pharmacology, health-related claims and benefits," Schweizerische Zeitschrift fur GanzheitsMedizin, vol. 20, no. 7-8, pp. 399-405, 2008.

[190] K. Ckiu, Y.-X. Liang, R. C.-C. Chang, and K.-F. So, “Lycium barbarum L.: a neuroprotective drug for glaucoma," Ophthalmology in China, vol. 20, no. 1, pp. 21-27, 2011.

[191] S. C. W. Sze, J. Song, R. C. C. Chang, K. Y. Zhang, R. N. S. Wong, and Y. Tong, "Research advances on the anti-aging profile of Fructus lycii: an ancient Chinese herbal medicine," Journal of Complementary and Integrative Medicine, vol. 5, no. 1, 2008.

[192] Z.-Z. Wang, X.-L. Lu, and Z.-P. Zhang, "Research progress in the improving effect of Fructus lycii on eyesight," Chinese Journal of New Drugs, vol. 22, no. 14, pp. 1648-1651, 2013.

[193] R. C.-C. Chang and K.-F. So, "Use of anti-aging herbal medicine, Lycium barbarum, against aging-associated diseases. What do we know so far?" Cellular and Molecular Neurobiology, vol. 28, no. 5, pp. 643-652, 2008.

[194] M. O. Woo and H. J. Park, "Regular articles: a study of the efficacy of physiological activities of herbal materials for cosmetics in 'Sanrimkyoungje," Journal of Investigative Cosmetology, vol. 9, no. 4, pp. 389-404, 2013.

[195] M. Ohsugi, W. Fan, K. Hase et al., "Active-oxygen scavenging activity of traditional nourishing-tonic herbal medicines and active constituents of Rhodiola sacra," Journal of Ethnopharmacology, vol. 67, no. 1, pp. 111-119, 1999.

[196] S. S. Kim, C. G. Hyun, J. S. Lee, J. H. Lim, J. Y. Kim, and D. H. Park, "In vitro screening of jeju medicinal plants for cosmeceutical materials," Journal of Applied Biological Chemistry, vol. 50, no. 4, pp. 215-220, 2007.

[197] Y.-J. Lee, E.-O. Kim, and S.-W. Choi, "Isolation and identification of antioxidant polyphenolic compounds in mulberry (Morus alba L.) seeds," Journal of the Korean Society of Food Science and Nutrition, vol. 40, no. 4, pp. 517-524, 2011.

[198] J. H. Kim, H. S. Chung, M. Kang et al., "Anti-diabetic effect of standardized herbal formula PM021 consisting of Mori Folium and Aurantii Fructus on type II diabetic Otsuka Long-Evans Tokushima Fatty (OLETF) rats," Diabetes Research and Clinical Practice, vol. 93, no. 2, pp. 198-204, 2011.

[199] H. N. Kwon, The effect of anti-wrinkle of Morus alba L. leaves water extract and its application as cosmetic materials using nano-encapsulation [Ph.D. thesis], Graduate School, Chonbuk National University, 2014.

[200] B. C. Park, Effects of Mori fructus on antioxidation, gene expression and cytokines of 3T3-L1 preadipocytes [Doctorate thesis], Graduate School, Sangji University, 2007. 
[201] C. B. Lee, Antioxidant and anti-inflammatory effects of cold and acrid release exterior herbs [M.S. thesis], Graduate School, Nambu University, 2012.

[202] M. J. Ryu, Skin functional activities of the extracts from various medicinal plants [Ph.D. thesis], Graduate School, Chosun University, 2009.

[203] I. S. Kwak, Comparison of different assays for evaluating antioxidant activity of polyphenols and tea extracts [Ph.D. thesis], Graduate School, Chonbuk National University, 2008.

[204] J. Y. Shin, "Screening of natural products that have activities against skin-aging," The Korean Journal of Food and Nutrition, vol. 14, no. 6, pp. 568-572, 2001.

[205] J. M. Lee, K. S. Shin, and H. J. Lee, "Determination of antioxidant vitamins in horticultural foods," Journal of the Korean Society of Dietary Culture, vol. 14, no. 2, pp. 167-175, 1999.

[206] J. Y. Jung, J. Y. Park, and H. S. Cheong, "Effect of Morus alba extract for hair growth promotion in C57BL/6 mouse," Journal of the Chosun Natural Science, vol. 1, no. 1, pp. 19-23, 2008.

[207] D. I. Kim, S. H. Park, J. M. Kim et al., "Effects of mulberry (Morus alba L.) leaf extract on oxygen radicals and their scavenger enzymes in liver of SD rats," Korean Society of Life Science, vol. 29, p. 98, 2000.

[208] P. Sillapakong, H. Yamamoto, M. Mangetsu et al., "Morus alba leaf extract increases lifespan in Caenorhabditis elegans," Journal of Insect Biotechnology and Sericology, vol. 80, no. 3, pp. 89-92, 2012.

[209] R. Kuwana, M. Morioka, A. Date, Y. Sawamura, O. Aki, and S. Arase, "The effect of Souhakuhi-extract on the hair cycle of New Zealand white rabbits and its topical therapy in male pattern baldness," Nishinihon Journal of Dermatology, vol. 58, no. 4, pp. 619-624, 1996.

[210] J. H. Choi, D. I. Kim, S. H. Park et al., "Effects of mulberry (Morus alba L.) leaf extract on oxygen radicals and their scavenger enzymes in liver of SD rats," Journal of Life Sciences, vol. 10, no. 5, pp. 504-510, 2000.

[211] J. H. Choi, D. I. Kim, S. H. Park et al., "Effects of mulberry (Morus alba L.) leaf extract on oxygen radicals and their scavenger enzymes in brain of SD rats," Korean Journal of Life Science, vol. 10, no. 6, pp. 570-576, 2000.

[212] G. Alvin, N. Catambay, A. Vergara, and M. J. Jamora, "A comparative study of the safety and efficacy of $75 \%$ mulberry (Morus alba) extract oil versus placebo as a topical treatment for melasma: a randomized, single-blind, placebo-controlled trial," Journal of Drugs in Dermatology, vol. 10, no. 9, pp. 1025-1031, 2011.

[213] H. A. Jung, S. E. Jin, R. J. Choi et al., "Anti-amnesic activity of neferine with antioxidant and anti-inflammatory capacities, as well as inhibition of ChEs and BACE1," Life Sciences, vol. 87, no. 13-14, pp. 420-430, 2010.

[214] H. Y. Chung, "Frontier symposium 7: plant diversity symposium, anti-aging action of Nelumbo nucifera and kaempferol based on molecular inflammation hypothesis of aging," in Proceedings of the Spring Scientific Meeting and General Assembly of the Biochemical Society of the Republic of Korea, p. 122, 2004.

[215] H. A. Jung, Y. J. Jung, N. Y. Yoon et al., "Inhibitory effects of Nelumbo nucifera leaves on rat lens aldose reductase, advanced glycation endproducts formation, and oxidative stress," Food and Chemical Toxicology, vol. 46, no. 12, pp. 3818-3826, 2008.

[216] S. Y. Lee, Skin controlling effects of the extrats of lotus root (nelumbo nucfifera gaertner) evaluations of free radical scavenging activity and inhibitory activities of tyrosinase and nitric oxide production and clinical questionnaire investigation on improvement effects of skin condition [M.S. thesis], Graduate School, Chung-ang University, 2009.

[217] W. M. Yang, H. M. Kim, M. S. Chang et al., "Effects of ethanol extract of Nelumbo nucifera leaves on anti-oxidation and type I procollagen expression in CCD-986sk cells," The Korean Journal of Oriental Medical Prescription, vol. 14, no. 2, pp. 67-75, 2006.

[218] M. S. Chang, E. B. Ko, H. J. Lee et al., "The effects of Nelumbo nucifera on utraviolet-B irradiated human keratinocytes," The Korea Journal of Herbology, vol. 26, no. 2, pp. 45-49, 2011.

[219] S. Bhuvana, R. Mahesh, and V. H. Begum, "Effect of Nelumbo nucifera flowers on plasma lipids and glucose in young, middleaged and aged rats," Pharmacologyonline, vol. 2, pp. 863-874, 2008.

[220] J. A. Evans-Johnson, J. A. Garlick, E. J. Johnson, X.-D. Wang, and C.-Y. O. Chen, "A pilot study of the photoprotective effect of almond phytochemicals in a 3D human skin equivalent," Journal of Photochemistry and Photobiology B, vol. 126, pp. 1725, 2013.

[221] B. C. Cha and E. H. Lee, "Antioxidant and hyaluronidase inhibition activities of Prunus persica batsch var. davidiana maximowicz," in Proceedings of the Convention of the Pharmaceutical Society of Korea, vol. 2, p. 200, 2003.

[222] S. Han, J.-K. Hwang, K.-K. Park et al., "Anti-photoaging effects of 2-methoxy-5-(2-methyl propyl) pyrazine isolated from peach (Prunus persica (L.) Batsch)," Food Science and Biotechnology, vol. 19, no. 6, pp. 1667-1671, 2010.

[223] N. R. T. Damasceno, A. Pérez-Heras, M. Serra et al., "Crossover study of diets enriched with virgin olive oil, walnuts or almonds. Effects on lipids and other cardiovascular risk markers," Nutrition, Metabolism and Cardiovascular Diseases, vol. 21, pp. S14S20, 2011.

[224] B. C. Cha and E. H. Lee, "Antioxidant and antiinflammation activities of Prunus persica tree extracts," Korean Journal of Medicinal Crop Science, vol. 12, no. 4, pp. 289-294, 2004.

[225] O. Boyd, P. Weng, X. Sun et al., "Nectarine promotes longevity in Drosophila melanogaster," Free Radical Biology and Medicine, vol. 50, no. 11, pp. 1669-1678, 2011.

[226] D. L. Croteau, N. C. de Souza-Pinto, C. Harboe et al., "DNA repair and the accumulation of oxidatively damaged DNA are affected by fruit intake in mice," Journals of Gerontology ABiological Sciences and Medical Sciences, vol. 65, no. 12, pp. 13001311, 2010.

[227] D. J. Gong, G. W. Kim, and B. S. Koo, "Effect of do-in (Prunus persica L. BATSCH) water extract (PPE) on concentration of extracellular acetylcholine in the rat hippocampus," Journal of Korean Oriental Medicine, vol. 25, no. 4, pp. 1-7, 2004.

[228] E. Mazzio, S. Deiab, K. Park, and K. F. A. Soliman, "High throughput screening to identify natural human monoamine oxidase B inhibitors," Phytotherapy Research, vol. 27, no. 6, pp. 818-828, 2013.

[229] J. Y. Kim and H. Lee, "A study on the effect of herbalacupuncture with phellodendri cortex solution on collageninduced arthritis in DBA/1J mice," The Korean Journal of Meridian \& Acupoint, vol. 24, no. 2, pp. 163-184, 2007.

[230] H. S. Kim, Antioxidant and antibacterial activities of Pinus koraiensis extracts with chitosan [M.S. thesis], Seoul National University of Science and Technology Graduate School, 2013.

[231] E. S. Kim, Effect of dried leaf powders and ethanol extracts of persimmon, green tea pine needle lipid metabolism and antioxidative capacity in rats [M.S. thesis], Graduate School 
Ewha Womans University, Seodaemun District, Republic of Korea, 1998.

[232] Z. Liang, F. Shi, Y. Wang et al., "Neuroprotective effects of tenuigenin in a SH-SY5Y cell model with 6-OHDA-induced injury," Neuroscience Letters, vol. 497, no. 2, pp. 104-109, 2011.

[233] Y. Chen, X. Huang, W. Chen, N. Wang, and L. Li, “Tenuigenin promotes proliferation and differentiation of hippocampal neural stem cells," Neurochemical Research, vol. 37, no. 4, pp. 771777, 2012.

[234] J. H. Jung, Experimental studies about the inhibitory effect on tyrosinase and elastase activities by various herb medicines [M.S. thesis], Graduate School, Kyungwon University, 2008.

[235] W. J. Han, H. S. Kim, S. T. Kim, T. H. Kim, H. W. Kang, and Y. S. Lyu, "Comparative effects of radix polygalae and rhizoma acori graminei on CT105-induced neuroblastoma cell lines," The Korean Society of Oriental Neuropsychiatry, vol. 14, no. 2, pp. 95105, 2003.

[236] P. Liu, Y. Hu, D.-H. Guo et al., "Antioxidant activity of oligosaccharide ester extracted from Polygala tenuifolia roots in senescence-accelerated mice," Pharmaceutical Biology, vol. 48, no. 7, pp. 828-833, 2010.

[237] H. Zhang, T. Han, L. Zhang et al., "Effects of tenuifolin extracted from radix polygalae on learning and memory: a behavioral and biochemical study on aged and amnesic mice," Phytomedicine, vol. 15, no. 8, pp. 587-594, 2008.

[238] W. R. Chen, Y. N. Yan, H. L. Cui, and X. Y. Li, "Effects of tenuigenin on the expression of brain-derived neurotrophic factor and its receptor tyrosine protein kinase B in the hippocampus of Alzheimer's disease model rats," Chinese Journal of Contemporary Neurology and Neurosurgery, vol. 14, no. 5, pp. 421-426, 2014.

[239] Z. Li, Y. Liu, L. Wang et al., "Memory-enhancing effects of the crude extract of Polygala tenuifolia on aged mice," EvidenceBased Complementary and Alternative Medicine, vol. 2014, Article ID 392324, 10 pages, 2014.

[240] K. Y. Shin, J.-Y. Lee, B. Y. Won et al., "BT-11 is effective for enhancing cognitive functions in the elderly humans," Neuroscience Letters, vol. 465, no. 2, pp. 157-159, 2009.

[241] S. V. More, H. Kumar, S. M. Kang, S. Y. Song, K. Lee, and D. K. Choi, "Advances in neuroprotective ingredients of medicinal herbs by using cellular and animal models of Parkinson's disease," Evidence-Based Complementary and Alternative Medicine, vol. 2013, Article ID 957875, 15 pages, 2013.

[242] A. Thapliyal, P. Semwal, T. Kapoor, P. Anthwal, and B. Sati, "Herbal extract as potential modulator and drug for synaptic plasticity and neurodegenerative disorders," International Journal of Pharmaceutical Sciences Review and Research, vol. 25, no. 1, pp. 69-79, 2014.

[243] M.-J. R. Howes and E. Perry, "The role of phytochemicals in the treatment and prevention of dementia," Drugs and Aging, vol. 28, no. 6, pp. 439-468, 2011.

[244] Y. Su, Q. Wang, C. Wang, K. Chan, Y. Sun, and H. Kuang, "The treatment of Alzheimer's disease using Chinese medicinal plants: from disease models to potential clinical applications," Journal of Ethnopharmacology, vol. 152, no. 3, pp. 403-423, 2014.

[245] Z.-K. Sun, H.-Q. Yang, and S.-D. Chen, "Traditional Chinese medicine: a promising candidate for the treatment of Alzheimer's disease," Translational Neurodegeneration, vol. 2, no. 1, article 6, 2013.

[246] D. S. Park, S. M. Shin, and K. H. Leem, "Effects of polygonati rhizoma extracts on the collagenase activity and procollagen synthesis in Hs68 human fibroblasts and tyrosinase activity," The Korea Journal of Herbology, vol. 28, no. 3, pp. 1-5, 2013.

[247] Y. Shan, X.-Y. Pan, D. Jiang, Y. S. Jin, and L. Z. Zhang, "Experimental observation on the effect of Polygonatum odoratum polysaccharide on anti-aging," Chinese Journal of Clinical Rehabilitation, vol. 10, no. 3, pp. 79-81, 2006.

[248] Y. Shan, X.-Y. Pan, D. Jiang, Y.-S. Jin, and L.-Z. Zhao, "Effect of Polygonatum odoratum polysaccharide on anti-oxidation system and immunological function of senile mice," Chinese Journal of Clinical Rehabilitation, vol. 10, no. 11, pp. 135-137, 2006.

[249] B. Shen, J. Truong, R. Helliwell, S. Govindaraghavan, and N. J. Sucher, "An in vitro study of neuroprotective properties of traditional Chinese herbal medicines thought to promote healthy ageing and longevity," BMC Complementary and Alternative Medicine, vol. 13, article 373, 2013.

[250] Z. Hongyan and X. Jinjun, "Recent advances in the study of antiaging action of Siberian Solomonseal (Polygonatum sibiricum)," Chinese Traditional and Herbal Drugs, vol. 30, no. 10, pp. 795796, 1999.

[251] M. G. Kim and K. H. Leem, "Effects of polygoni multiflori radix on the elastase, and collagenase activities and the procollagen synthesis in Hs68 human fibroblasts," The Korea Journal of Herbology, vol. 29, no. 1, pp. 7-12, 2014.

[252] J. Y. Jang, H. N. Kim, Y. R. Kim et al., "Hexane extract from Polygonum multiflorum attenuates glutamate-induced apoptosis in primary cultured cortical neurons," Journal of Ethnopharmacology, vol. 145, no. 1, pp. 261-268, 2013.

[253] G. Lv, H. Gu, S. Chen, Z. Lou, and L. Shan, "Pharmacokinetic profile of $2,3,5,4^{\prime}$-tetrahydroxystilbene-2-O- $\beta$ - $D$-glucoside in mice after oral administration of Polygonum multiflorum extract," Drug Development and Industrial Pharmacy, vol. 38, no. 2, pp. 248-255, 2012.

[254] S. A. Lee and D. Y. Yoo, "Protective effect of Polygonum multiflorum on cell damage in UVB-irradiated HaCaT keratinocytes," The Journal of Oriental Gynecology, vol. 24, no. 4, pp. 31-49, 2011.

[255] W. Wang, J. H. Wang, and T. R. Shi, "Effect of Polygonum multiflorum on the life-span and lipid metabolism in senile Japanese quails," Zhong Xi Yi Jie He Za Zhi, vol. 8, no. 4, pp. 223-198, 1988.

[256] J. Chen, "An experimental study on the anti-senility effects of shou xing bu zhi," Zhongguo Zhong Xi Yi Jie He Za Zhi, vol. 9, no. 4, pp. 226-227, 1989.

[257] I. K. Hwang, K.-Y. Yoo, D. W. Kim et al., "An extract of Polygonum multiflorum protects against free radical damage induced by ultraviolet B irradiation of the skin," Brazilian Journal of Medical and Biological Research, vol. 39, no. 9, pp. 1181-1188, 2006.

[258] YC. Chan, MF. Wang, and SC. Chan, "Effects of Polygonum multiflorum thunb. Extracts on learning, memory and brain morphology in aged mice," Taiwanese Journal of Agricultural Chemistry and Fo, vol. 40, no. 5, pp. 370-376, 2002.

[259] R. Wang, Y. Tang, B. Feng et al., "Changes in hippocampal synapses and learning-memory abilities in age-increasing rats and effects of tetrahydroxystilbene glucoside in aged rats," Neuroscience, vol. 149, no. 4, pp. 739-746, 2007.

[260] Y. C. Chan, M. F. Wang, and H. C. Chang, "Polygonum multiflorum extracts improve cognitive performance in senescence accelerated mice," The American Journal of Chinese Medicine, vol. 31, no. 2, pp. 171-179, 2003.

[261] L. Zhang, Y. Xing, C.-F. Ye, H.-X. Ai, H.-F. Wei, and L. Li, "Learning-memory deficit with aging in APP transgenic mice 
of Alzheimer's disease and intervention by using tetrahydroxystilbene glucoside," Behavioural Brain Research, vol. 173, no. 2, pp. 246-254, 2006.

[262] H. N. Kim, Y. R. Kim, J. Y. Jang et al., "Neuroprotective effects of Polygonum multiflorum extract against glutamateinduced oxidative toxicity in HT22 hippocampal cells," Journal of Ethnopharmacology, vol. 150, no. 1, pp. 108-115, 2013.

[263] Y.-C. Chan, F.-C. Cheng, and M.-F. Wang, "Beneficial effects of different Polygonum multiflorum Thunb. extracts on memory and hippocampus morphology," Journal of Nutritional Science and Vitaminology, vol. 48, no. 6, pp. 491-497, 2002.

[264] X. X. Zhou, Q. Yang, Y. H. Xie et al., "Protective effect of tetrahydroxystilbene glucoside against $\mathrm{D}$-galactose induced aging process in mice," Phytochemistry Letters, vol. 6, no. 3, pp. 372-378, 2013.

[265] L. Lv, Y. Cheng, T. Zheng, X. Li, and R. Zhai, "Purification, antioxidant activity and antiglycation of polysaccharides from Polygonum multiflorum Thunb," Carbohydrate Polymers, vol. 99, pp. 765-773, 2014.

[266] S. J. Song, F. F. Li, and H. Yue, "Study on the anti-aging effects of radix Polygonum multiflorum," Journal of the Hebei Medical University, vol. 24, no. 2, pp. 90-91, 2003.

[267] L. Zhang, S. Yu, R. Zhang, Y. Xing, Y. Li, and L. Li, “Tetrahydroxystilbene glucoside antagonizes age-related $\alpha$-synuclein overexpression in the hippocampus of APP transgenic mouse model of Alzheimer's disease," Restorative Neurology and Neuroscience, vol. 31, no. 1, pp. 41-52, 2013.

[268] L. Chen, J. Huang, and L. Xue, "Effect of compound Polygonum multiflorum extract on Alzheimer's disease," Zhong Nan Da Xue Xue Bao Yi Xue Ban, vol. 35, no. 6, pp. 612-615, 2010.

[269] T. B. Ng, H. X. Wang, F. Liu, and L. X. Xia, "Plants beneficial to the aging brain," Neuroembryology and Aging, vol. 3, no. 3, pp. 136-141, 2006.

[270] W. Wang and D.-Q. Wang, "Progress of study on brain protective effect and mechanism of Polygonum multiflorum," Chinese Journal of Integrated Traditional and Western Medicine, vol. 25, no. 10, pp. 955-959, 2005.

[271] Y. Wang, L. Q. Huang, X. C. Tang, and H. Y. Zhang, "Retrospect and prospect of active principles from Chinese herbs in the treatment of dementia," Acta Pharmacologica Sinica, vol. 31, no. 6, pp. 649-664, 2010.

[272] J. H. Lee, K. M. Lee, J. S. Kim, T. Y. Jung, and S. C. Lim, "Antiwrinkle effects of Cervi pantotrichum Cornu pharmacopuncture solution," Journal of Korean Acupuncture \& Moxibustion Medicine Society, vol. 27, no. 4, pp. 1-8, 2010.

[273] G.-L. Mo, Y. Li, R.-H. Du, D.-Z. Dai, X.-D. Cong, and Y. Dai, "Isoproterenol induced stressful reactions in the brain are characterized by inflammation due to activation of NADPH oxidase and ER stress: attenuated by apocynin, rehmannia complex and triterpene acids," Neurochemical Research, vol. 39, no. 4, pp. 719-730, 2014.

[274] X. L. Zhang, B. Jiang, Z. B. Li, S. Hao, and L. J. An, “Catalpol ameliorates cognition deficits and attenuates oxidative damage in the brain of senescent mice induced by D-galactose," Pharmacology Biochemistry and Behavior, vol. 88, no. 1, pp. 64-72, 2007.

[275] X. L. Zhang, L. J. An, Y. M. Bao, J. Y. Wang, and B. Jiang, "d-galactose administration induces memory loss and energy metabolism disturbance in mice: protective effects of catalpol," Food and Chemical Toxicology, vol. 46, no. 8, pp. 2888-2894, 2008.
[276] J. Liu, Q.-J. He, W. Zou et al., “Catalpol increases hippocampal neuroplasticity and up-regulates PKC and BDNF in the aged rats," Brain Research, vol. 1123, no. 1, pp. 68-79, 2006.

[277] K. H. Lee, Anti-oxidative effects of radix rehmanniae recens and preparata on toxic agent induced kidney cell injury [M.S. thesis], Graduate School, Dong-Shin University, 2003.

[278] S. I. Cho, "Anti oxidative effects of RADIX rehmanniae preparata on toxic agent induced kidney cell injury," The Korea Journal of Herbology, vol. 18, no. 4, pp. 119-126, 2003.

[279] I. Darrat, N. Ahmad, K. Seidman, and M. D. Seidman, "Auditory research involving antioxidants," Current Opinion in Otolaryngology and Head and Neck Surgery, vol. 15, no. 5, pp. 358-363, 2007.

[280] K.-H. Lee and E.-M. Choi, "Rubus coreanus Miq. extract promotes osteoblast differentiation and inhibits bone-resorbing mediators in MC3T3-E1 cells," The American Journal of Chinese Medicine, vol. 34, no. 4, pp. 643-654, 2006.

[281] H.-S. Lee and J. A. Yoon, "Inhibitory activity of advanced glycation endproducts (age) formation of edible plants for development of anti-wrinkle ingredients," Journal of the Korean Society of Food Science and Nutrition, vol. 39, no. 2, pp. 186-192, 2010.

[282] Y. J. Kwak, D. H. Lee, N. M. Kim, and J. S. Lee, "Screening and extraction condition of anti-skin aging elastase inhibitor from medicinal plants," Korean Journal of Medicinal Crop Science, vol. 13, no. 6, pp. 213-216, 2005.

[283] H. S. Jeong, J. H. Ha, Y. Kim et al., "Effects of Rubus coreanus extracts on ultraviolet-A irradiated cultured human skin fibroblasts," Korean Journal of Medicinal Crop Science, vol. 17, no. 5, pp. 321-327, 2009.

[284] H. C. Lee, S. G. Hwang, Y. C. Lee et al., "Screening of the acetylcholinesterase inhibitors from water extracts of the medicinal plants," Korean Journal of Oriental Physiology \& Pathology, vol. 16, no. 2, pp. 215-219, 2002.

[285] S. H. Do, J.-W. Lee, W.-I. Jeong et al., "Bone-protecting effect of Rubus coreanus by dual regulation of osteoblasts and osteoclasts," Menopause, vol. 15, no. 4, part 1, pp. 676-683, 2008.

[286] S. J. Park, S. S. Baek, J. W. Lee, S. J. Kim, and K. H. Kim, "Effect of Rubi Fructus (fruit of Rubus coreanus Miq.) on antioxidant capacity in D-galactose induced aging rats," The Korean Journal of Oriental Preventive Medical Society, vol. 8, no. 1, pp. 75-87, 2004.

[287] K. G. Lee, X. Cui, and J. P. Lim, "Effects of rubi fructus water extract on oxygen free radical metabolizing enzyme activites," Korean Journal of Oriental Physiology \& Pathology, vol. 16, no. 5, pp. 911-913, 2002.

[288] M.-R. Choi, M. Y. Lee, J. E. Kim et al., "Rubus coreanus Miquel improves on impairment of memory in senescence-accelerated mouse (SAM)," Journal of the Korean Society of Food Science and Nutrition, vol. 41, no. 9, pp. 1253-1258, 2012.

[289] S.-M. Park, H.-Y. Choi, E.-J. Lee et al., "Dietary supplementation of red ginseng, Chinese lizard's tail, and Korean raspberry extracts alleviate oxidative stresses in aged rats," Food Science and Biotechnology, vol. 19, no. 4, pp. 967-972, 2010.

[290] T. Osawa, "Antioxidative phytochemicals and biomarkers," Journal of Food and Drug Analysis, vol. 20, supplement 1, pp. 350354, 2012.

[291] M. G. Dilshara, R. G. P. T. Jayasooriya, C.-H. Kang et al., “Downregulation of pro-inflammatory mediators by a water extract of Schisandra chinensis (Turcz.) Baill fruit in lipopolysaccharidestimulated RAW 264.7 macrophage cells," Environmental Toxicology and Pharmacology, vol. 36, no. 2, pp. 256-264, 2013. 
[292] M. Fu, Z.-H. Sun, M. Zong, X.-P. He, H.-C. Zuo, and Z.-P. Xie, "Deoxyschisandrin modulates synchronized $\mathrm{Ca}^{2+}$ oscillations and spontaneous synaptic transmission of cultured hippocampal neurons," Acta Pharmacologica Sinica, vol. 29, no. 8, pp. 891898, 2008.

[293] S.-M. Park, J.-J. Kim, K.-Y. Jeong, S.-K. Han, T.-H. Jeong, and M.-Y. Yun, "Antioxidant activity and inhibition of MMP1 expression of schizandrae fructus (Schizandra chinensis) extract," Korean Journal of Pharmacognosy, vol. 44, no. 1, pp. 4752, 2013.

[294] J. H. Lee, H. W. Yang, S. M. Bak, and K. S. Yoo, "Effect of schisandrae fructus on cultured mouse cerebral neurons damaged by hydrogen peroxide," Korean Journal of Oriental Physiology \& Pathology, vol. 17, no. 1, pp. 101-104, 2003.

[295] H. H. Park, Effect of Schisandrae chinensis fructus on keratinocyte damage by UV irradiation [Doctoral thesis], Graduate School, Wonkwang University, 2012.

[296] E. J. Jeong, H. K. Lee, K. Y. Lee et al., “The effects of lignanriched extract of Shisandra chinensis on amyloid- $\beta$-induced cognitive impairment and neurotoxicity in the cortex and hippocampus of mouse," Journal of Ethnopharmacology, vol. 146, no. 1, pp. 347-354, 2013.

[297] K. M. Ko, N. Chen, H. Y. Leung, E. P. K. Leong, M. K. T. Poon, and P. Y. Chiu, "Long-term schisandrin B treatment mitigates age-related impairments in mitochondrial antioxidant status and functional ability in various tissues, and improves the survival of aging C57BL/6J mice," BioFactors, vol. 34, no. 4, pp. 331-342, 2008.

[298] D. Ma, Q. Li, J. Du, Y. Liu, S. Liu, and A. Shan, "Influence of mannan oligosaccharide, Ligustrum lucidum and Schisandra chinensis on parameters of antioxidative and immunological status of broilers," Archives of Animal Nutrition, vol. 60, no. 6, pp. 467-476, 2006.

[299] P. Y. Lam and K. M. Ko, "Schisandrin B as a hormetic agent for preventing age-related neurodegenerative diseases," Oxidative Medicine and Cellular Longevity, vol. 2012, Article ID 250825, 9 pages, 2012.

[300] S.-W. Chan, "Panax ginseng, Rhodiola rosea and Schisandra chinensis," International Journal of Food Sciences and Nutrition, vol. 63, no. 1, pp. 75-81, 2012.

[301] H. Liu, F. Liang, W. Su et al., "Lifespan extension by $n$-butanol extract from seed of Platycladus orientalis in Caenorhabditis elegans," Journal of Ethnopharmacology, vol. 147, no. 2, pp. 366$372,2013$.

[302] K. T. Lee, K. H. Cho, Y. H. Shon, K. S. Nam, and J. K. Lim, "Screening of xanthium sibiricum patr. Aqua-acupuncture solution as the cancer chemopreventive agent," Korean Journal of Acupuncture, vol. 18, no. 2, pp. 7-12, 2001.

[303] B. I. Seo, Effects of the Cervi Cornu on the aged ovariectomized rat model of postmenopausal osteoporosis [Doctorate thesis], Graduate School, Kyung Hee University, 1998.

[304] J. H. Lee, Y. J. Heo, S. N. Lee et al., "Effects of Rehmanniae Radix Preparata extracts on the collagenase activity and procollagen synthesis in HS68 human fibroblasts and tyrosinase activity," Journal of the Institute Oriental Medicine, vol. 13, no. 1, pp. 1-13, 2010.

[305] J. G. Kim and K. S. Kim, "Original article: inhibitory effects of cervi pantotrichum cornu herbal acupuncture on type 2 collagen-induced arthritis," Journal of Korean Acupuncture \& Moxibustion Medicine Society, vol. 19, no. 6, pp. 155-170, 2002.
[306] Y. H. Choi, W. S. Choi, I. K. Song, J. S. Park, S. D. Lee, and K. S. Kim, "Protective and anti-arthritic effects of Cervi pantotrichum Cornu herbal acupuncture, inhibiting dihydroorotate dehydrogenase, on phosphate ions-mediated chondrocyte apoptosis and rat Collagen-induced arthritis," The Journal of Korean Acupuncture Moxibustion Society, vol. 19, no. 5, pp. 1027, 2002.

[307] H. J. Lee, H. S. Cho, M. S. Hwang et al., "Effect of Cervi pantotrichum cornu pharmacopuncture on suppressing the expression of iNOS and production of NO in type 2 collageninduced arthritis mice," Journal of Korean Acupuncture \& Moxibustion Medicine Society, vol. 25, no. 5, pp. 105-116, 2008.

[308] D. K. Ahn and S. D. Shim, "Effects of the Cerbi Cornu on the aged ovariectomized rat model of postmenopausal osteoporosis," The Korea Journal of Herbology, vol. 14, no. 1, pp. 153-166, 1999.

[309] B. J. Choi, Modulation of bone mass, strength and turnover by a Cervi pantotrichum cornu herbal acupuncture in adjuvantinduced arthritic rats [M.S. thesis], Graduate School, Dongguk University, 2002.

[310] C. Lee, J. H. Jang, B. A. Kim, and C. I. Park, "Anti-aging effects of marine natural extracts against UVB-induced damages in human skin cells," Journal of the Society of Cosmetic Scientists of Korea, vol. 38, no. 3, pp. 255-261, 2012.

[311] J. H. Jang, C. Lee, S. C. Kim, J. W. Chung, and C. I. Park, "Protective effect of marine natural products against uvbinduced damages in human skin fibroblast via antioxidant mechanism," Journal of the Society of Cosmetic Scientists of Korea, vol. 36, no. 1, pp. 79-87, 2010.

[312] G. Y. Seo, S. W. Lee, S. J. Park et al., "Biological activities of hominis placenta herbal acupuncture prepared by hydrochloric acid hydrolysis," Journal of Pharmacopuncture, vol. 13, no. 2, pp. 5-12, 2010.

[313] J. C. Seo, J. H. Chung, and B. C. Ahn, "The antiapoptic effects of Hominis placenta extract," Journal of Korean Pharmacopuncture Institute, vol. 4, no. 1, pp. 123-124, 2001.

[314] J. M. Yang, T. K. Lee, and D. I. Kim, "Jahage, Hominis placenta (HP), suppress bone resorption by inhibition of tyrosine kinase Src, cyclooxygenase expression and PGE2 synthesis," The Journal of Oriental Gynecology, vol. 20, no. 4, pp. 56-73, 2007.

[315] Y. W. Jo, S. W. Lee, M. J. Kang, E. J. Kim, S. D. Lee, and K. S. Kim, "Effect of Hominis placenta herbal acupuncture on type II collagen-induced arthritis in mice," The Journal of Korean Acupuncture \& Moxibustion Society, vol. 24, no. 6, pp. 75-88, 2007.

[316] R. S. Kim, J. H. Cho, J. B. Jang, and K. S. Lee, "The effect of Hominis placenta on reproductive performance in aged mice," The Journal of Oriental Obstetrics \& Gynecology, vol. 15, no. 2, pp. 56-69, 2002.

[317] H. T. Hong, "Suppression of Jahage (Hominis placenta) on prostaglandin E2 synthesis, alkaline phosphatase and plasminogen activator activities in the mouse calvarial bone cells," Oriental Pharmacy and Experimental Medicine, vol. 1, no. 1, pp. 57-63, 2001.

[318] K. H. Choi, S. E. Hong, Y. J. Seo, and B. R. Park, "Effects of Hominis placenta on the ovariectomized rat model of postmenopausal osteoporosis," The Journal Of Oriental Gynecology, vol. 12, no. 2, pp. 75-100, 1999.

[319] D. Harman, "Role of free radicals in aging and disease," in Relations between Normal Aging and Disease, pp. 45-84, Raven Press, New York, NY, USA, 1985. 
[320] B. P. Yu, C.-M. Kang, J.-S. Han, and D. S. Kim, "Can antioxidant supplementation slow the aging process?" BioFactors, vol. 7, no. 1-2, pp. 93-101, 1998.

[321] H. Y. Chung, H. J. Kim, J. W. Kim, and B. P. Yu, "The inflammation hypothesis of aging: molecular modulation by calorie restriction," Annals of the New York Academy of Sciences, vol. 928, pp. 327-335, 2001.

[322] H. Y. Chung, H. J. Kim, K. W. Kim, J. S. Choi, and B. P. Yu, "Molecular inflammation hypothesis of aging based on the antiaging mechanism of calorie restriction," Microscopy Research and Technique, vol. 59, no. 4, pp. 264-272, 2002.

[323] V. M. Dilman, S. Y. Revskoy, and A. G. Golubev, "Neuroendocrine-ontogenetic mechanism of aging: toward an integrated theory of aging," International Review of Neurobiology, vol. 28, pp. 89-156, 1986.

[324] J. Miquel, "An update on the oxygen stress-mitochondrial mutation theory of aging: genetic and evolutionary implications," Experimental Gerontology, vol. 33, no. 1, pp. 113-126, 1998.

[325] U. T. Brunk and A. Terman, "Lipofuscin: mechanisms of agerelated accumulation and influence on cell function," Free Radical Biology and Medicine, vol. 33, no. 5, pp. 611-619, 2002.

[326] L. Hayflick, "The limited in vitro lifetime of human diploid cell strains," Experimental Cell Research, vol. 37, no. 3, pp. 614-636, 1965.

[327] M. Armanios, J. K. Alder, E. M. Parry, B. Karim, M. A. Strong, and C. W. Greider, "Short telomeres are sufficient to cause the degenerative defects associated with aging," The American Journal of Human Genetics, vol. 85, no. 6, pp. 823-832, 2009. 


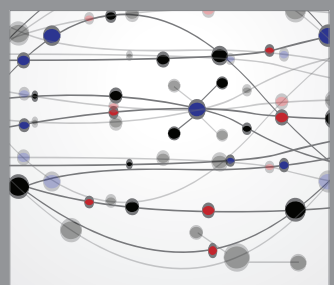

The Scientific World Journal
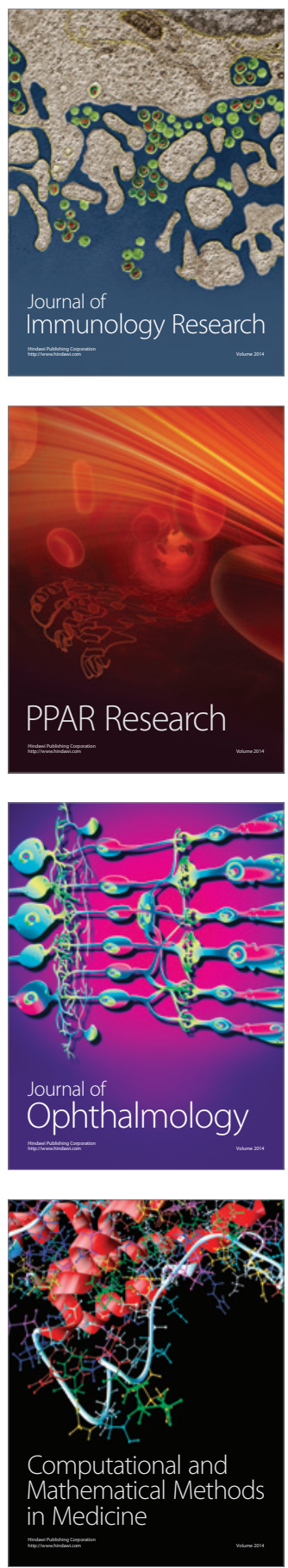

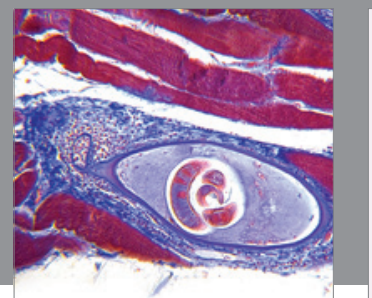

Gastroenterology

Research and Practice
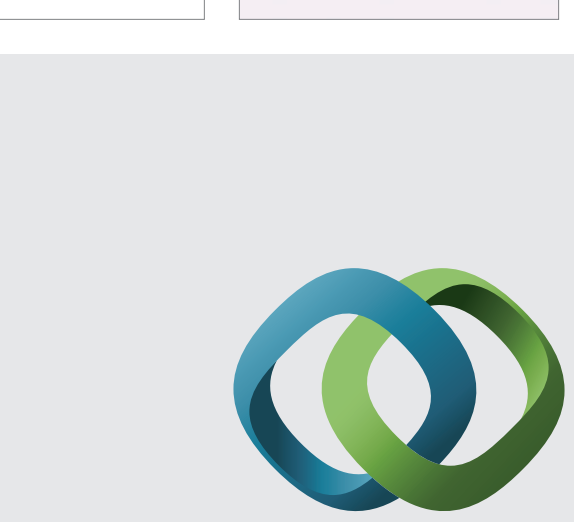

\section{Hindawi}

Submit your manuscripts at

http://www.hindawi.com
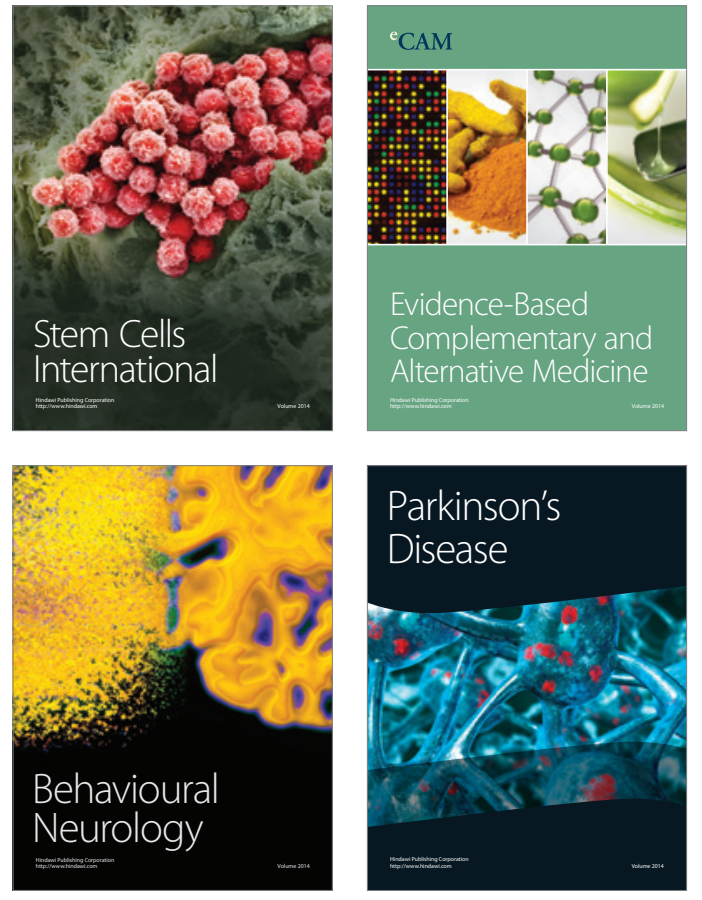
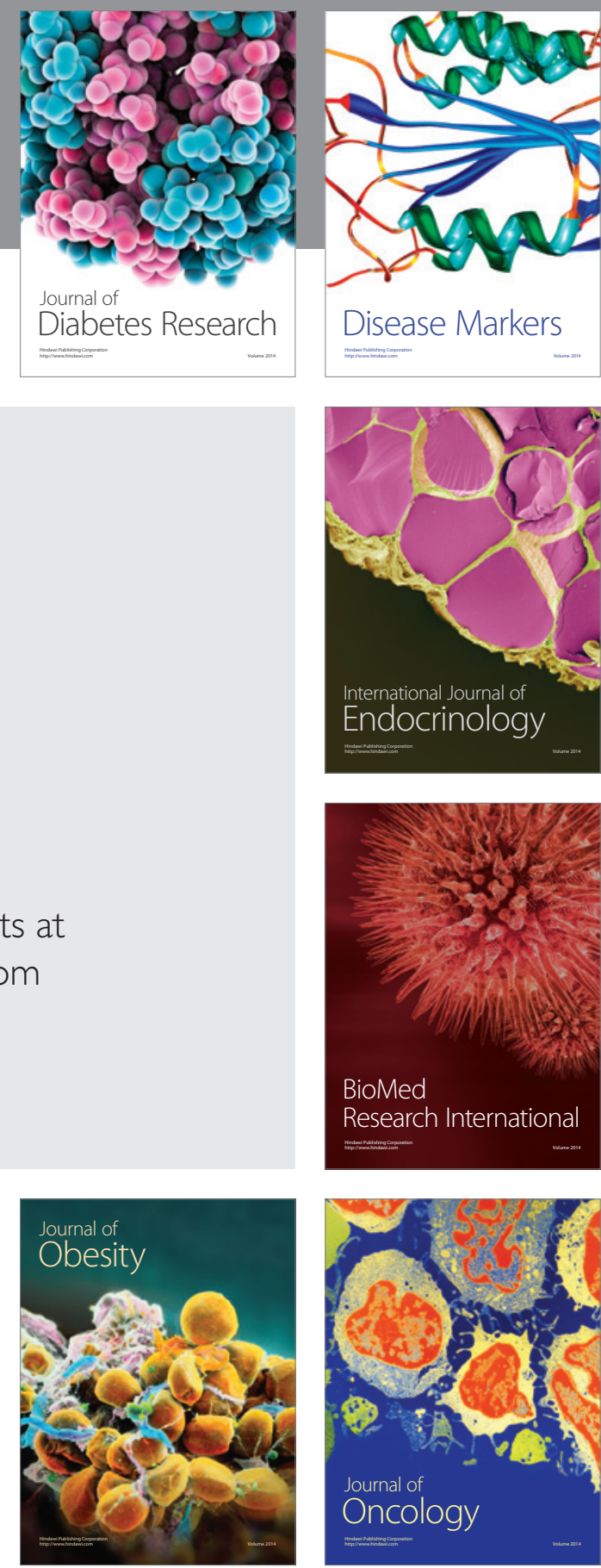

Disease Markers
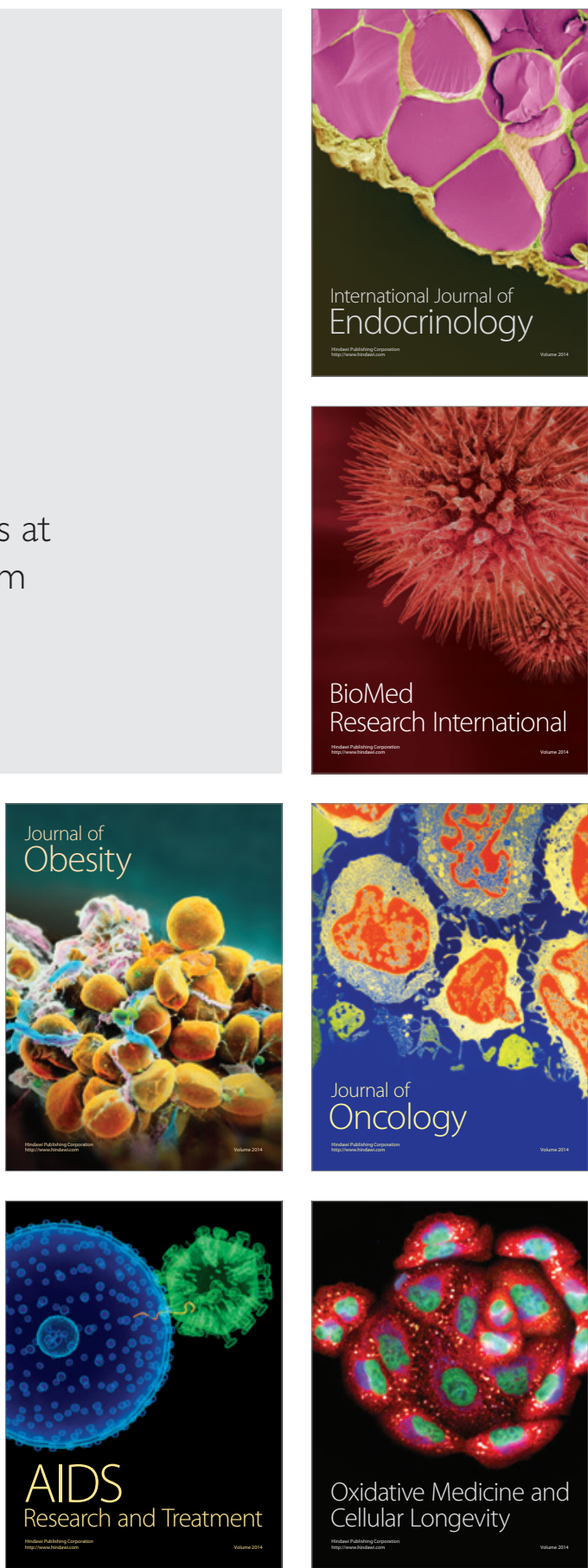